University of Wollongong

Research Online

Faculty of Engineering and Information

Faculty of Engineering and Information

Sciences - Papers: Part A

Sciences

$1-1-2016$

\title{
Mechanical recoverability and damage process of ionic-covalent PAAm- alginate hybrid hydrogels
}

\author{
Hai Xin \\ University of Wollongong, hxin@uow.edu.au \\ Hugh Ralph Brown \\ University of Wollongong, hbrown@uow.edu.au \\ Sina Naficy \\ University of Wollongong, snaficy@uow.edu.au \\ Geoffrey M. Spinks \\ University of Wollongong, gspinks@uow.edu.au
}

Follow this and additional works at: https://ro.uow.edu.au/eispapers

Part of the Engineering Commons, and the Science and Technology Studies Commons

Research Online is the open access institutional repository for the University of Wollongong. For further information contact the UOW Library: research-pubs@uow.edu.au 


\title{
Mechanical recoverability and damage process of ionic-covalent PAAm-alginate hybrid hydrogels
}

\begin{abstract}
Hydrogels consisting of interpenetrating networks of ionically and covalently crosslinked polymers showed high toughness and mechanical recoverability as a result of the dissociation and re-formation of ionic crosslinks. The present investigation aimed to provide a quantitative study on the mechanical recoverability and damage process of an example hybrid gel of calcium crosslinked alginate and covalently crosslinked polyacrylamide. Three series of load/unload tests were performed sequentially with the mechanical properties of the gel fully retrieved between the 2 nd and 3 rd load/unload series while only the partial recovery of mechanical properties was evident from the $1 \mathrm{st}$ to 2 nd series. The load/ unload curves in the three series were modeled by existing mechanical models, and the fitted model parameters clearly demonstrate a damage process for the hybrid gel. When a hybrid gel was deformed above its historic maximum strain, the shortest alginate chains were fully-stretched, pulling apart the weak ionic crosslinks and dissipating fracture energy. Consequently, the strand density of the intact gel network was reduced and the contour length of the remaining next-shortest load-bearing alginate chains became longer. A log-normal distribution was used to describe the probability distribution for the strand fracture and also to describe the strand length distribution of the ionic network. (C) 2015 Wiley

Periodicals, Inc.
\end{abstract}

\section{Keywords}

recoverability, damage, process, ionic, mechanical, covalent, hydrogels, paam, alginate, hybrid

\section{Disciplines}

Engineering | Science and Technology Studies

\section{Publication Details}

Xin, H., Brown, H. R., Naficy, S. \& Spinks, G. M. (2016). Mechanical recoverability and damage process of ionic-covalent PAAm-alginate hybrid hydrogels. Journal of Polymer Science Part B: Polymer Physics, 54 (1), 53-63. 


\title{
Mechanical Recoverability and Damage Process
}

\author{
of Ionic-Covalent PAAm-Alginate Hybrid
}

\section{Hydrogels}

Hai Xin ${ }^{a}$, Hugh R. Brown ${ }^{a, b}$, Sina Naficy ${ }^{a, b}$ and Geoffrey M. Spinks* ${ }^{a, b}$

${ }^{a}$ ARC Centre of Excellence for Electromaterials Science and Intelligent Polymer Research Institute, University of Wollongong, Innovation Campus, Squires Way, North Wollongong, NSW, 2522, Australia.

${ }^{b}$ School of Mechanical, Materials and Mechatronic Engineering, University of Wollongong, Wollongong, NSW, 2522, Australia.

*to whom all the correspondence should be addressed

Tel+6124220 3010; gspinks@uow.edu.au 


\section{Abstract}

Hydrogels consisting of interpenetrating networks of ionically and covalently crosslinked polymers show high toughness and mechanical recoverability as a result of the dissociation and re-formation of ionic crosslinks. The present investigation aims to provide a quantitative study on the mechanical recoverability and damage process of an example hybrid gel of calcium crosslinked alginate and covalently crosslinked polyacrylamide. Three series of load/unload tests were performed sequentially with the mechanical properties of the gel fully retrieved between the $2^{\text {nd }}$ and $3^{\text {rd }}$ load/unload series while only the partial recovery of mechanical properties was evident from the $1^{\text {st }}$ to $2^{\text {nd }}$ series. The load/unload curves in the three series were modeled by existing mechanical models, and the fitted model parameters clearly demonstrate a damage process for the hybrid gel. When a hybrid gel was deformed above its historic maximum, the shortest alginate chains were fully-stretched, pulling apart the weak ionic crosslinks and dissipating fracture energy. Consequently, the strand density of the intact gel network was reduced and the contour length of the remaining next-shortest load-bearing alginate chains became longer. A log-normal distribution was used to describe the probability distribution for the strand fracture and also to describe the strand length distribution of the ionic network.

Keyword: hydrogel, mechanical properties, recoverability, toughness. 


\section{Introduction}

Tough hydrogel materials such as double network hydrogel ${ }^{1}$, nano-composite hydrogel ${ }^{2}$, and slide-ring hydrogel ${ }^{\underline{3}}$ have recently attracted broad interest due to their excellent mechanical properties and unique network structures. The advent of these mechanically robust hydrogels significantly expands the frontier where the hydrogels can be used. Extensive advances have been made to explain the toughening mechanism of these gel systems or to produce other types of tough hydrogel materials. In the case of double network (DN) hydrogels, high toughness occurs with interpenetrating networks of relatively high and low crosslink densities and with a high mass ratio of loose network to tight network 4 Toughness originates from energy dissipation due to scission of the tight network chains and where the presence of the loose network retards crack propagation ${ }^{5,6}$. Similarly, nanocomposite hydrogels may be toughened when the nano-particles act as high functionality crosslinks spanned by multiple network strands. The shorter strands fracture at smaller strains,

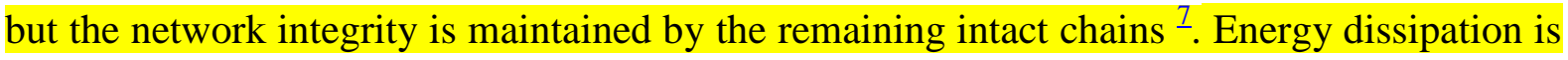
also enhanced by the breakage of bonds between the polymer and nanoparticles $\stackrel{8}{\text {. }}$

Recently, a novel type of hydrogel consisting of an interpenetrating polymer network has been reported. The gel system is the combination of an ionically crosslinked network and a covalently crosslinked network. Ionic crosslinks are formed between divalent cations (such as $\mathrm{Ca}^{2+}$ ) and polysaccharides such as gellan gum, kappa carrageenan, or alginate while epoxy-amine or polyacrylamide are used to prepare the interpenetrating covalently crosslinked network. Since the gel contains two polymer networks with different types of

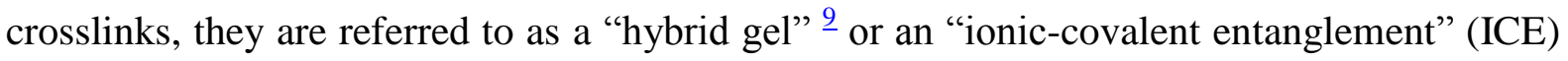
gel $\stackrel{10}{ }$. Suo and co-workers ${ }^{9}$ report a hybrid hydrogel consisting of an ionically crosslinked 
alginate and a covalently crosslinked polyacrylamide. The divalent cation $\mathrm{Ca}^{2+}$ was used as the ionic crosslinker to chelate the guluronic blocks on the alginate chains to form zip-like

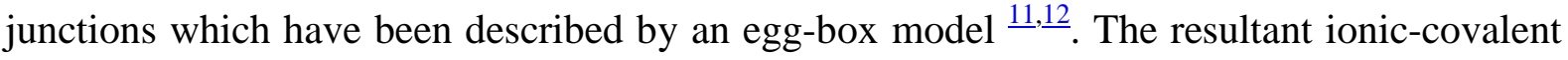
hybrid gels exhibit high fracture toughness (fracture energy reaches $9000 \mathrm{~J} / \mathrm{m}^{2}$ ) and remarkable extensibility (extended to $>20$ times its original length) on the basis of a tightlycrosslinked alginate and a loosely-crosslinked polyacrylamide. The high fracture toughness of the hybrid gel originates from the energy dissipated due to the re-coiling of stretched alginate chains that occurs upon dissociation of ionic crosslinks under load. Unlike the DN system where the fracture toughness is derived from the scission of "sacrificial covalent

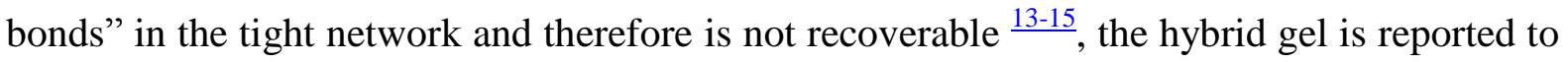
be recoverable in mechanical properties, due to the ionic bonds that are pulled apart under the external stress and are re-formed at zero stress. The pronounced hysteresis between the first loading and unloading curve was retrieved in the subsequent load/unload cycles to varying

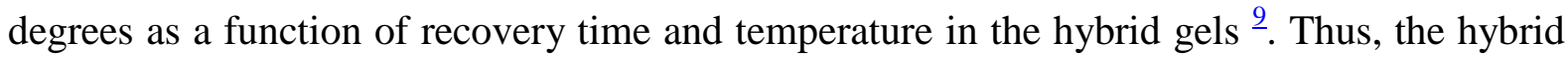
gel is distinct from the conventional DN system and becomes a promising candidate for many load-bearing applications such as artificial muscles. However, to advance the realisation of the hybrid gel in these proposed applications, several questions still need to be answered such as whether or not the mechanical properties of the hybrid gel are fully recoverable and what is the detailed damage process that occurs in a strained hybrid gel.

The present work aims to answer the above two questions by performing sequential load/unload tests on the ionic-covalent PAAm-alginate hybrid gel. Three series of load/unload tests were sequentially carried out on the virgin gel, and the gel after a $1^{\text {st }}$ and $2^{\text {nd }}$ recovery process. Each series consisted of four load/unload cycles with increased maximum 
extension ratio $\left(\lambda_{\max }\right)$. Such a strategy was used before to demonstrate the mechanical recoverability of ionic-covalent entanglement hydrogel $\stackrel{10}{ }$ and also proved to be useful to obtain continuous information on the mechanical recoverability and damage process of different hydrogels $\stackrel{15-18}{\text {. }}$

Wang and Hong (W-H) $\stackrel{19}{ }$ have proposed a model that quantitatively demonstrates the damage mechanism occurring during extension of a double network hydrogel. The W-H model utilised Gent's description of the limited extensibility of rubber networks $\underline{20}$. Assuming a log-normal distribution for the strand length of the tight network in a DN gel, Wang and Hong have developed a model that accurately simulates the loading and unloading stressextension curves in a one example DN gel. The model was successfully applied to a wider

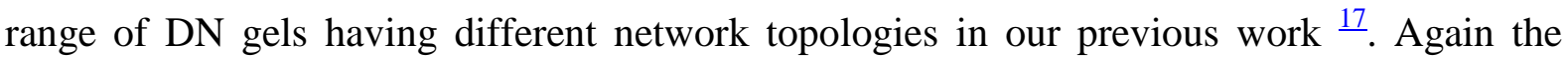
agreement between the calculated and experimental load/unload stress curves was satisfactory and the process provided a means for estimating the strand length distribution of the tight covalent network $\frac{17}{}$. In the present work, the $\mathrm{W}-\mathrm{H}$ model has been used in an attempt to quantify the recoverability and damage process occurring in the hybrid gel system. The model was used here to fit the load/unload results for the tested hybrid gel in three series of load/unload tests. The model parameters were considered to be indicators of the network topology of the tightly crosslinked alginate network. 


\section{Experimental}

\subsection{Materials}

$40 \mathrm{wt} \%$ aqueous acrylamide (Sigma-Aldrich) solution was used to prepare covalently crosslinked PAAm network. The radical initiator and covalent crosslinking agent for polymerization of AAm was potassium persulfate (KPS; Sigma-Aldrich) and N,N'methylenebisacrylamide (MBAA; Sigma-Aldrich), respectively. Sodium alginate from brown algae (Alg; Sigma-Aldrich) was used to prepare the ionically crosslinked network. Calcium chloride $\left(\mathrm{CaCl}_{2}\right.$; Sigma-Aldrich) was used as the ionic crosslinker. All solutions were prepared with deionized water and chemical reagents were used as received.

\subsection{Hydrogel preparation}

The gels used in the present study were ionic-covalent PAAm-alginate hybrid gel prepared with a covalent crosslinker concentration of $0.01 \mathrm{~mol} \%$ or $0.05 \mathrm{~mol} \%$. In detail, 0.1 mol\% KPS and $0.01 \mathrm{~mol} \%$ or $0.05 \mathrm{~mol} \%$ MBAA were dissolved in $40 \mathrm{wt} \%$ aqueous AAm solution. The concentration of KPS and MBAA was with respect to the molar concentration of AAm. $1.33 \mathrm{~g}$ alginate was dissolved into $22 \mathrm{~g}$ deionized water to make the alginate solution. Both solutions were then mixed together to produce the final polymerisation solution with $12 \mathrm{wt} \%$ AAm and $4 \mathrm{wt} \%$ alginate. Nitrogen was used to bubble the solution for 40 minutes before it was degassed in a vacuum environment for $2 \mathrm{~h}$ to remove dissolved oxygen. The gel solution was then transferred into a glass reaction mould consisting of a 2 $\mathrm{mm}$ thick silicone rubber spacer sandwiched by two glass plates, and the mould was placed in a $60{ }^{\circ} \mathrm{C}$ fanned oven for $6 \mathrm{~h}$ to finalize the polymerisation. The obtained covalentlycrosslinked gel was immersed in $2 \mathrm{wt} \% \mathrm{CaCl}_{2}$ solution for 5 days to ionically crosslink the 
alginate. Before any mechanical test was conducted, the hybrid gels were soaked in deionized water for a few days to reach the swelling equilibrium. The shear moduli at the swelling equilibrium were $58 \mathrm{kPa}$ and $41 \mathrm{kPa}$ for the gels prepared with $0.01 \mathrm{~mol} \%$ and $0.05 \mathrm{~mol} \%$ crosslinker, respectively.

\subsection{Three series load/unload test}

The test was carried out on an EZ-S mechanical tester (Shimadzu, Japan). A dogbone shaped sample was used with gauge length of $12 \mathrm{~mm}$ and width of $2 \mathrm{~mm}$. Strain was determined by grip displacement with crosshead rate at $10 \mathrm{~mm} / \mathrm{min}$, and the extension ratio ( $\lambda$ ) was calculated as the ratio of present sample length to its original length. Standard rubber elasticity theory shown in equation (1) was fitted to engineering stress $(\sigma)$ and extension ratio $(\lambda)$ to a maximum extension of 1.3 to calculate shear modulus $(\mu)^{21}$.

$$
\sigma=\mu\left(\lambda-\frac{1}{\lambda^{2}}\right)
$$

The whole test procedure comprised of three series of load/unload tests sequentially performed on the virgin gel, and the damaged gel after a $1^{\text {st }}$ recovery and a $2^{\text {nd }}$ recovery process. Each series was composed of four load/unload cycles with sequentially increased maximum extension ratio $\left(\lambda_{\max }\right)$. The sequence of $\lambda_{\max }$ in each series was consistent hence the gel underwent identical deformation history in each series. In one load/unload cycle, the sample gel was first stretched to a set strain and then relaxed to zero stress. The subsequent cycle with a larger $\lambda_{\max }$ was performed immediately. 


\subsection{Gel recovery}

After $1^{\text {st }}$ and $2^{\text {nd }}$ load/unload series, the damaged gel was allowed to recover. The gel was wrapped with polyethylene film and soaked in silicone oil. It was then placed in a $60{ }^{\circ} \mathrm{C}$ fanned oven for $1 \mathrm{~h}$ to recover the test-induced damage. A small, gradual accumulation of water loss was observed throughout the recovery procedure. Therefore, the gel before the next mechanical test was re-immersed in excess deionized water, and its mass was measured periodically until the swelling ratio returned to the same level of the virgin state. The gel was then wrapped with polyethylene film and immersed in silicon oil for $1 \mathrm{~h}$ in order for the justabsorbed water to evenly distribute within the gel network. The mass and dimension of the tested gel were carefully measured at each step throughout the whole procedure to ensure there was not significant dehydration which could affect the test results.

\section{Results and Discussion}



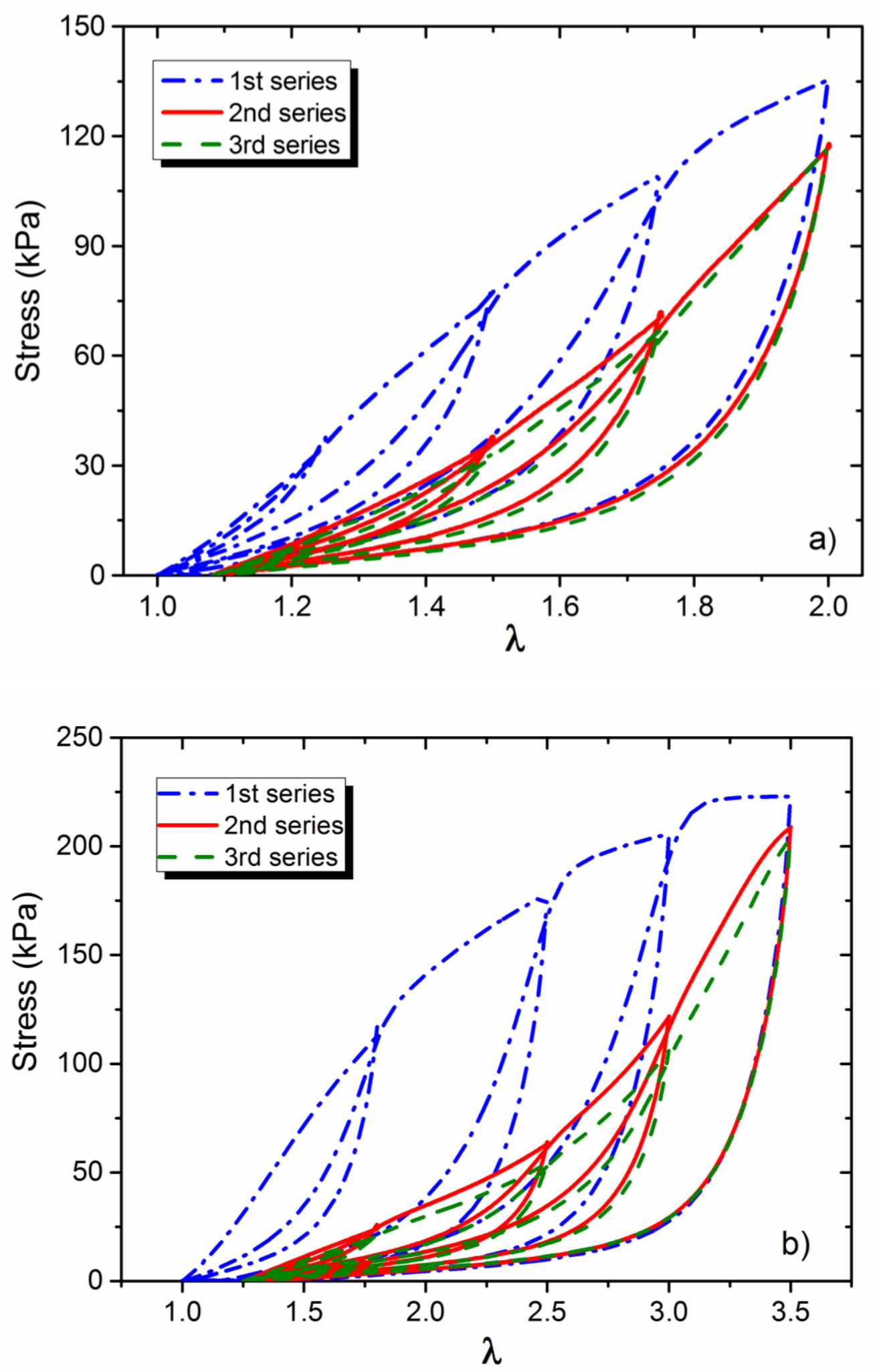

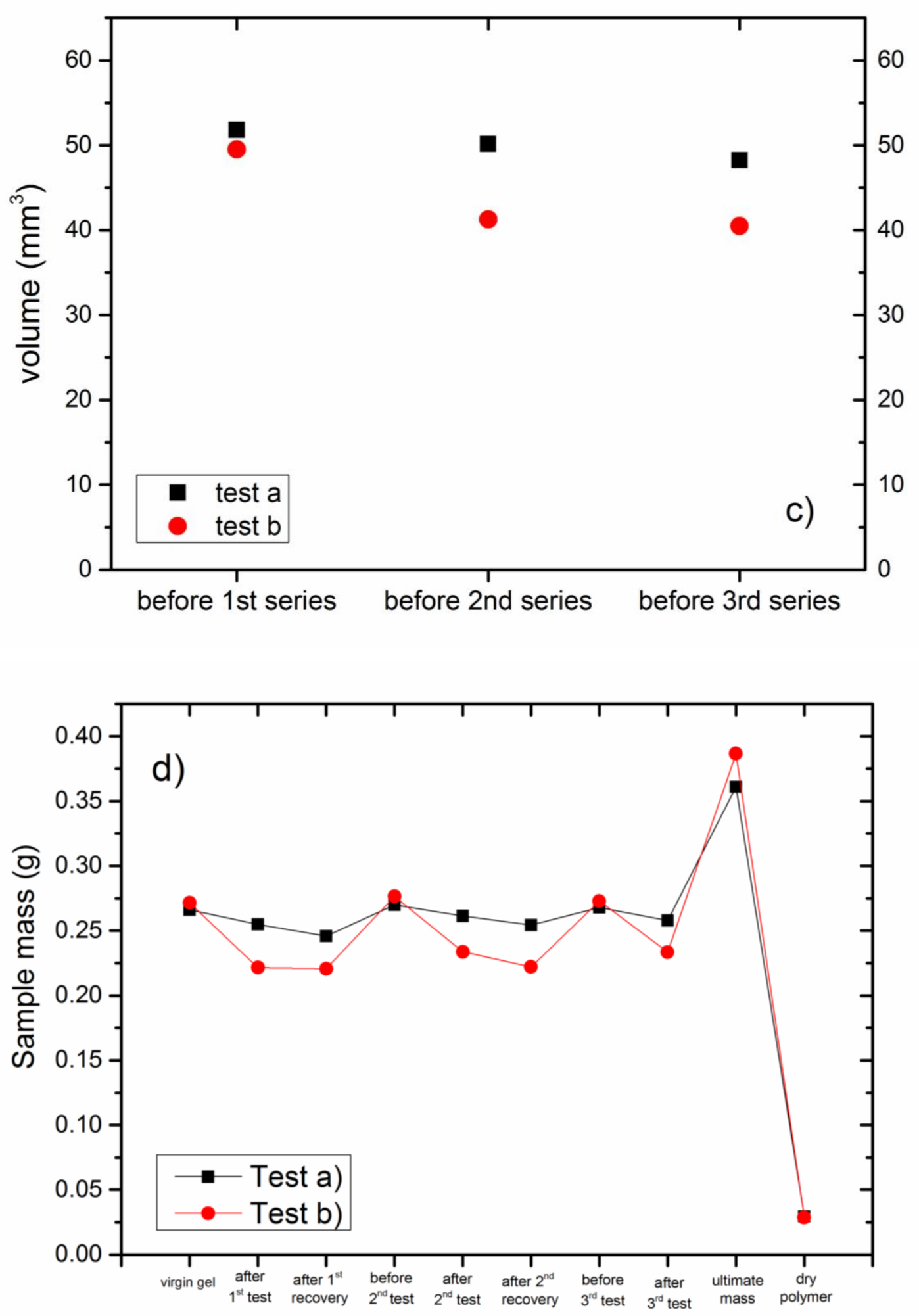

Figure 1 Three series of load/unload tests sequentially performed on virgin gel (first series) and the gel after $1^{\text {st }}$ (second series) and $2^{\text {nd }}$ recovery (third series). Recovery involved holding 
the unloaded gel at $60^{\circ} \mathrm{C}$ for one hour in a silicone oil bath to limit water loss, followed by rehydration to the initial virgin gel swelling ratio and equilibrating for one hour at room temperature. The global maximum extension ratio was 2.0 and 3.5 in a) and b), respectively. The volume of gauge length section of dumbbell samples (cross-sectional area x length) (c) and mass (d) of the sample gel measured at different stages in tests shown in parts a) and b).

Figure 1 demonstrates the stress-extension curves for the three series of load/unload tests performed on the PAAm-alginate hybrid gel prepared with MBAA concentration at 0.05 mol\%. Each series comprised four load/unload cycles. $\lambda_{\max }$ was successively $1.25,1.5,1.75$ and 2 in test a) and 1.8, 2.5, 3, and 3.5 in test b). All the stresses an extension ratios in each of the three series were calculated with respect to the original dimensions of the virgin gel. After the initial series was complete, a $1 \mathrm{~mm}$ and $3 \mathrm{~mm}$ permanent strain was seen on the sample gel in test a) and b), respectively and maintained in the subsequent tests, hence the first-loading curve in the following two series started from and extension ratio of 1.08 in a) and $1.25 \mathrm{in} \mathrm{b}$ ). As described in the experimental section, to ensure the gel tested in the three series possessed approximately the same swelling ratio, before each imminent mechanical test, the gel was reimmersed in deionized water for a particular period of time until the mass returned to the same level of the virgin gel. Meanwhile, the length, width, and thickness of the gauge (the real stretched area) were measured before each series to guarantee there was not significant volumetric change in the gauge area due to dehydration. Figure $1 \mathrm{c}$ ) and d) indicate the gauge dimensions and total gel mass measured at each stage in test a) and b). It should be noticed in c) and d) that a slight volume decrease of the gauge area was seen for the sample gel before the $2^{\text {nd }}$ and $3^{\text {rd }}$ load/unload series in both test a) and b). The tested sample gel was dumbbell shaped, and only the gauge area was stretched during the mechanical test. The two ends of 
the sample were firmly clamped in the testing machine, and therefore, the polymer network of the clamped area was compressed and likely damaged. Although the total weight of the sample gel returned to the same level of the virgin state by re-swelling, a slight additional proportion of the water was considered to be absorbed by the clamped area, which accounted for the slight volumetric decrease due to dehydration in the gauge area.

From the test results, it is obvious that the hybrid gel exhibits different load/unload behaviour from that of DN gels such as reported in our previous work $\frac{17}{}$. Most significantly, the reloading stress in the subsequent cycle exceeds the unloading stress in the former cycle. In DN gels the reloading curve always follows the previous unloading curve $\stackrel{15-17}{ }$. The different behavior in the hybrid gels suggests the re-formation of fractured ionic bonds during the previous unloading process, as noted previously ${ }^{9,10}$. More importantly, the hysteresis and shear modulus in the initial series is partly retrieved in the following two series. Suo et al. $\underline{9}$ have reported that PAAm-alginate gel ionically crosslinked by $\mathrm{Ca}^{2+}$ ions shows pronounced hysteresis between first loading and unloading curve, and both hysteresis and initial stiffness can recover significantly if sufficient recovery duration is allowed. It is proposed that the mechanical recoverability is due to the re-formation of fractured ionic bonds forming the crosslinks between two alginate chains $\underline{9,10}$.

Another interesting phenomenon is that the mechanical properties are fully recovered from the $2^{\text {nd }}$ to the $3^{\text {rd }}$ series. It is clearly shown in Figure 1 a) and b) that the $3^{\text {rd }}$ series reproduce closely the load/unload curves in the $2^{\text {nd }}$ series. However the mechanical performance in the $1^{\text {st }}$ series is only partially recoverable. Both shear modulus and hysteresis in the $1^{\text {st }}$ series noticeably decrease in the subsequent tests. Presumably, the first-loading of 
the initial series introduces some irreversible network re-construction such as disentanglement of entrapped polymer strands or covalent bond scission, which dissipates a large amount of energy. Such a process will not occur in the following tests, reflected by the much reduced hysteresis. As shown in Figure $1 \mathrm{~d}$ ), the damaged gels following the $3^{\text {rd }}$ series were re-swollen in deionized water for 7 days to reach a new equilibrium. The swelling ratio of the damaged gel at the new equilibrium was found to be much larger than that of the virgin gel that was also swollen to equilibrium. Furthermore, the gauge length of the re-swollen gel is longer than that of the virgin gel. These results suggest a reduced strand density in the stretching direction caused by loading.

Our experimental work suggests that PAAm-alginate hybrid gels show necking during uniaxial stretching if prepared with a covalent crosslinker concentration at $0.01 \mathrm{~mol} \%$. Three series of load/unload tests were also carried out on this gel. The test and recovery procedure was identical as used in the two tests described above for the gel prepared with $0.05 \mathrm{~mol} \%$ covalent crosslinker. As before, the gel was re-soaked in deionized water to retrieve its virgin swelling ratio before conducting the $2^{\text {nd }}$ and $3^{\text {rd }}$ load/unload series. Here, for simplicity, each series only consisted of one stretch-relax cycle in which the gel was extended to $\lambda_{\max }=4$ to ensure the occurrence of necking during the initial loading. Figure 2 a) illustrates the stressstretch curves of the simplified load/unload tests performed on the $0.01 \mathrm{~mol} \%$ gel. Figure $2 \mathrm{~b}$ ) and c) shows the dimensions of the gauge area and the total mass of the sample gel measured at different stages in the test.

The stress-stretch curve of the $1^{\text {st }}$ series demonstrates a necking mechanism where the stress tends to plateau before it decreases slightly. Necking was visually observed for this $0.01 \mathrm{~mol} \%$ gel during the test as a cloudy and narrowed region which grew gradually until it 
propagated throughout the entire sample. However, the gel in the subsequent two series did not re-neck. The pronounced hysteresis and initial shear modulus in the $1^{\text {st }}$ series are partly recovered in the $2^{\text {nd }}$ series, and mechanical properties only become fully reversible between the $2^{\text {nd }}$ and $3^{\text {rd }}$ series. These test results again suggest that the loading process in the initial loading cycle triggers some irreversible network re-construction that dissipates a large amount of energy and would not occur in the subsequent tests. Thus, the mechanical properties of PAAm-alginate hybrid gel are not fully reversible until the network is reconstructed. Irreversible chain disentanglement or covalent bond scission are possible mechanisms accounting for the network re-construction.

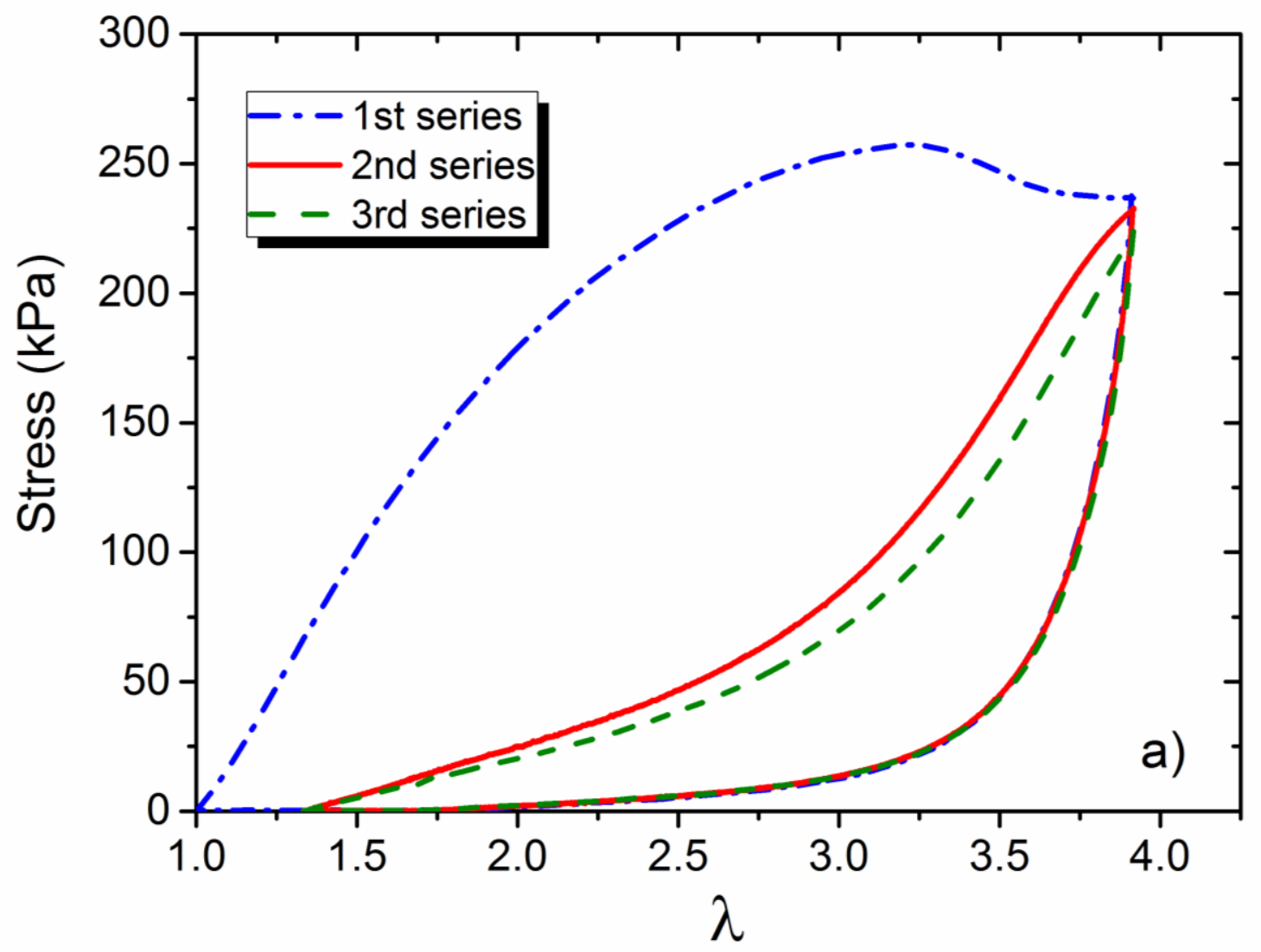



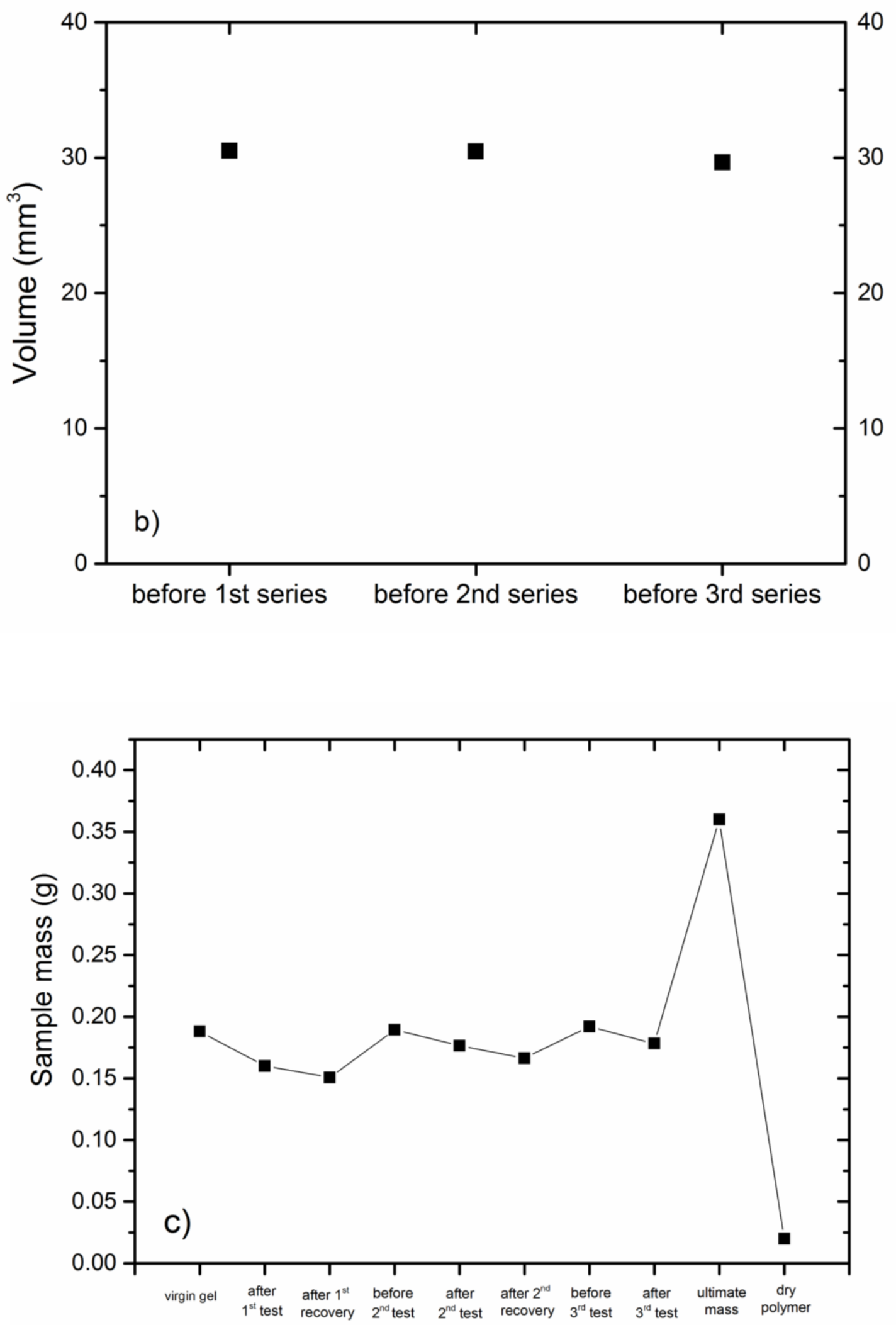
Figure 2 a) Stress-stretch curves of three series load/unload test performed on $0.01 \mathrm{~mol} \%$ gel with initiated necking during loading of the virgin gel $\left(1^{\text {st }}\right.$ series $)$ that was absent when the sample was tested after the first $\left(2^{\text {nd }}\right.$ series $)$ and second $\left(3^{\text {rd }}\right.$ series $)$ recovery periods; $\left.b\right)$ sample volumes measured before each of the three load/unload series; and c) sample mass measured at different stages throughout the whole test procedure.

A more quantitative analysis on load/unload test results was made by using the Gent and W-H mechanical models. Literature reports have suggested that a considerable number of strands in the tight network are already broken within the pre-yielding region for DN gels $\frac{15}{\text {. }}$ Yielding occurs at an extension ratio $\sim 3$ for the hybrid gel shown in Figure 2. Thus, the three load/unload series test with maximum extension ratio at 2 (shown in Figure 1 a)) is of the most interest in the present work. Standard rubber elasticity theory (equation 1) was fitted to the initial strain of each loading and unloading curve to determine the shear modulus of the

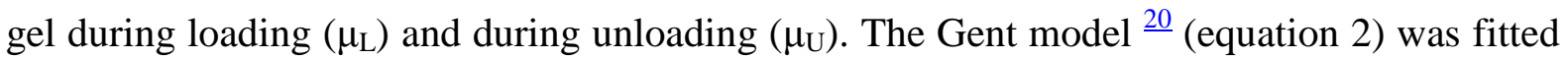
to the entire unloading curves in each of the three series and to obtain the maximum extensibility parameter $\mathrm{J}_{\mathrm{m}}$. Both $\mu$ and $\mathrm{J}_{\mathrm{m}}$ are indicators of the network topology of the tight network in the hybrid gel.

$\sigma=\mu \frac{\left(\lambda-\lambda^{-2}\right)}{\left(1-\frac{J_{1}}{J_{m}}\right)}$

Where $\mathrm{J}_{1}$ is first stretch invariant in the form of

$$
J_{1}=\lambda^{2}+2 \lambda^{-1}-3
$$


and $\mathrm{J}_{\mathrm{m}}$ is maximum network extensibility which is considered to be related to the contour length of the shortest elastic-active chains in the tight ionically-crosslinked alginate network.
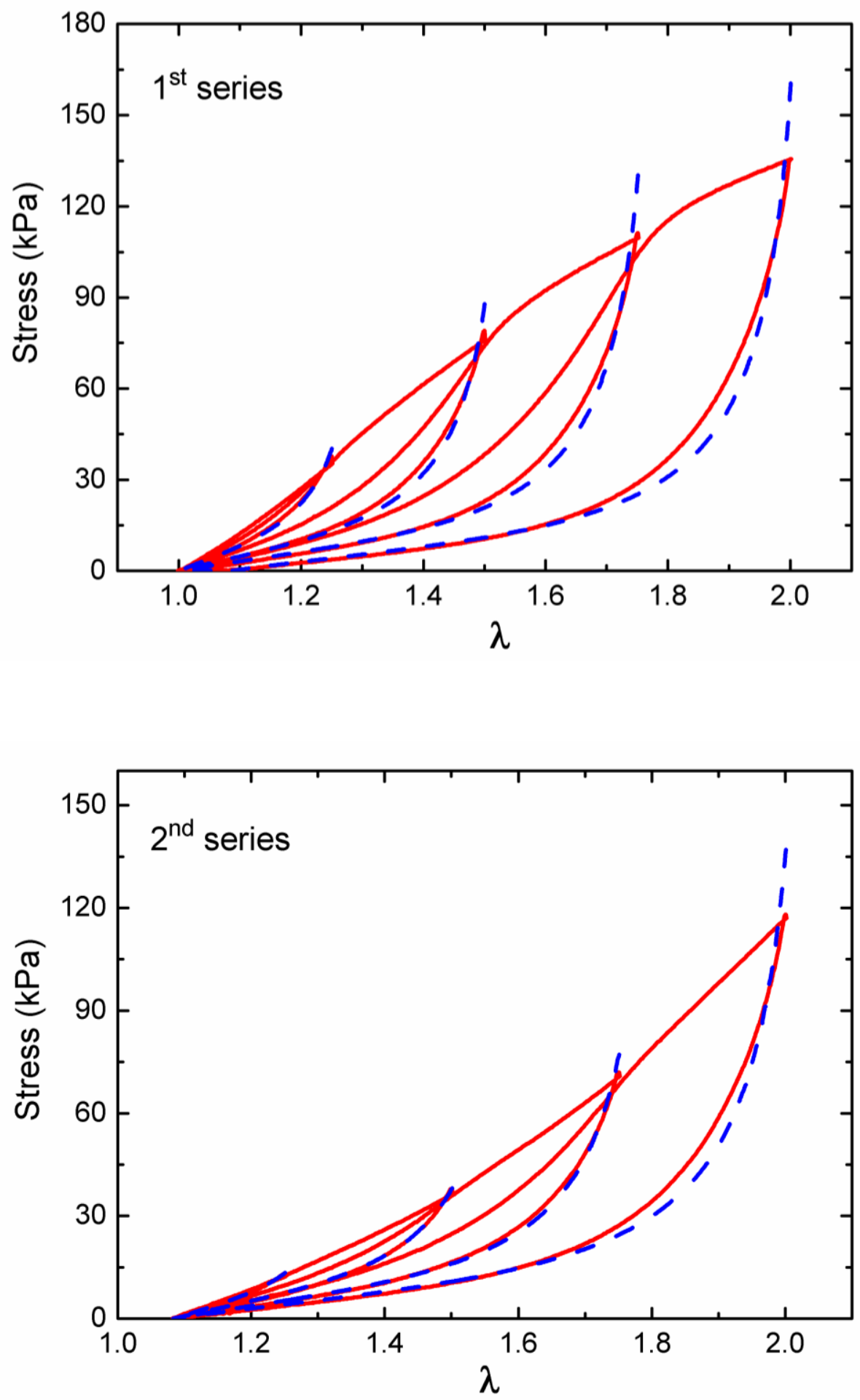


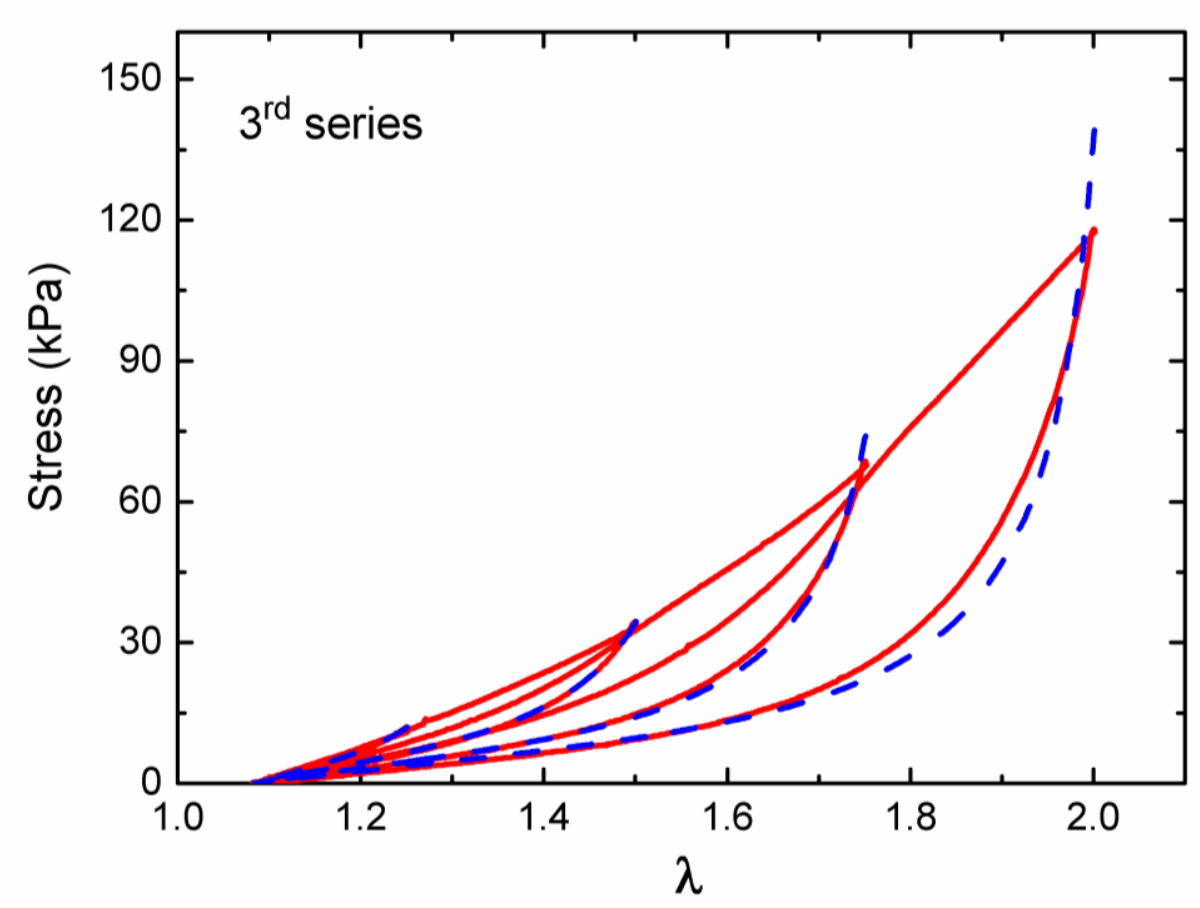

Figure 3 Gent model fits to the unloading curves for each load/unload series, as defined in Figure 1. Red solid curves are measured load/unload stress while the blue dashed lines are Gent model fits of unloading stress.

Figure 3 demonstrates a good agreement between measured unloading stress and Gent model fits in each series of load/unload tests. The two model parameters $\mu_{\mathrm{U}}$ and $\mathrm{J}_{\mathrm{m}}$ evolving with increasing historic maximum deformation $\left(\lambda_{\max }\right)$ are shown in Figure 4 a) and b), respectively. Clearly, $\mu_{\mathrm{U}}$ monotonically decreases with $\lambda_{\max }$ while $\mathrm{J}_{\mathrm{m}}$ shows a linear increase with $\mathrm{J}_{1 \max }$. In the Gent model, $\mu_{\mathrm{U}}$ represents the density of network strands and $\mathrm{J}_{\mathrm{m}}$ is associated with the contour length of the shortest strands. Previous studies have provided a general description of the fracture mechanism of the hybrid gel where multiple network strand breakages occur in the highly-crosslinked ionic (tight network) and are stabilised by the sparsely-crosslinked flexible covalent network (loose network) ${ }^{9,18}$. Thus, the variations of the two Gent model 
parameters indicate a damage process for the hybrid gel. When the gel is deformed above its historic maximum extension, the shortest alginate strands are fully-stretched, pulling apart the weak ionic crosslinks where $\mathrm{Ca}^{2+}$ ions connects two alginate chains. As a result, the density of the crosslinked alginate strands is reduced, leading to the gradual decrease of $\mu_{\mathrm{U}}$. At the same time, the length of the next-shortest alginate strands in the remaining network becomes longer, which is reflected by the increase of $\mathrm{J}_{\mathrm{m}}$. The presence of PAAm chains allows the accumulation of microscopic damages in the alginate network, avoiding the occurrence of gross fracture.

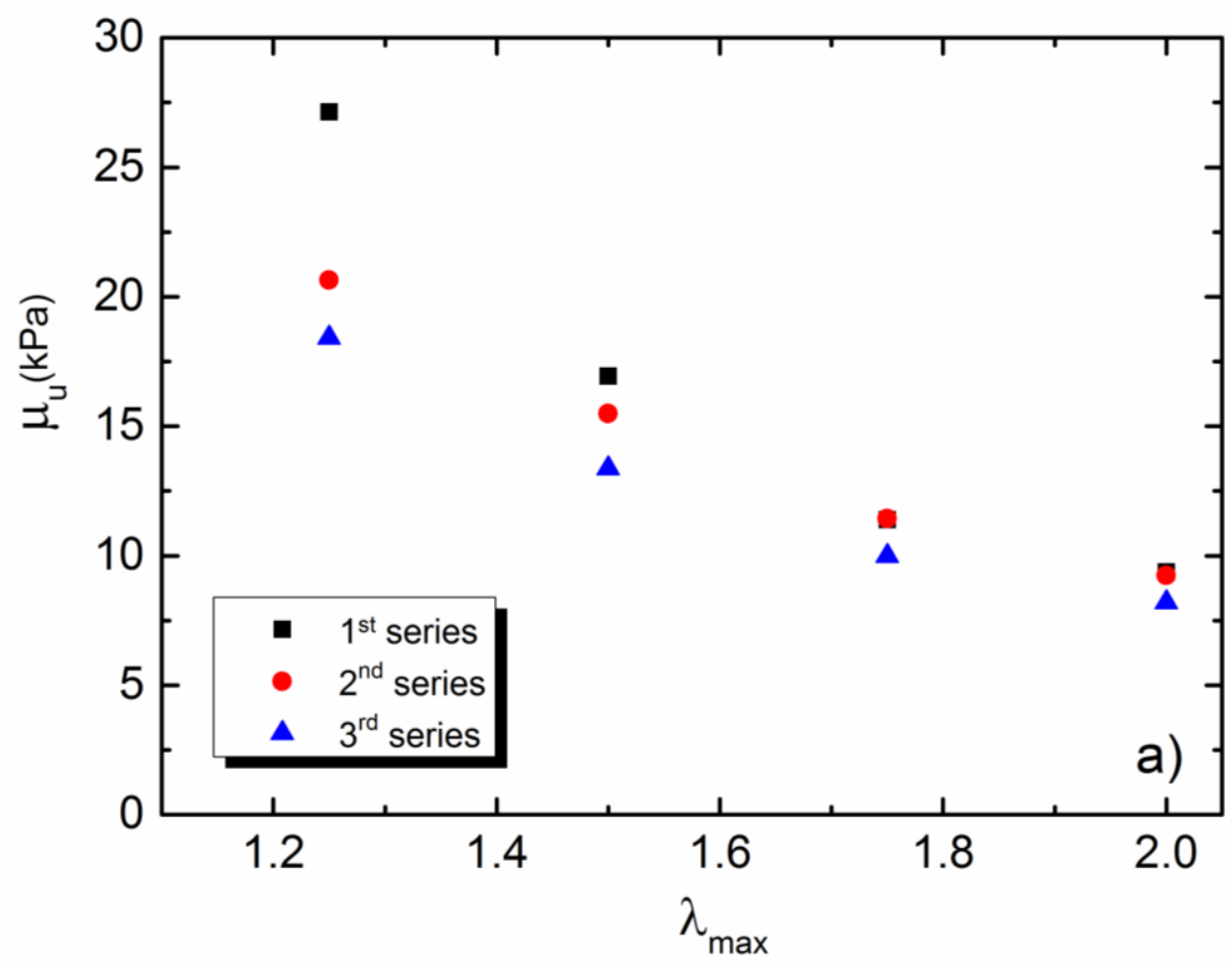



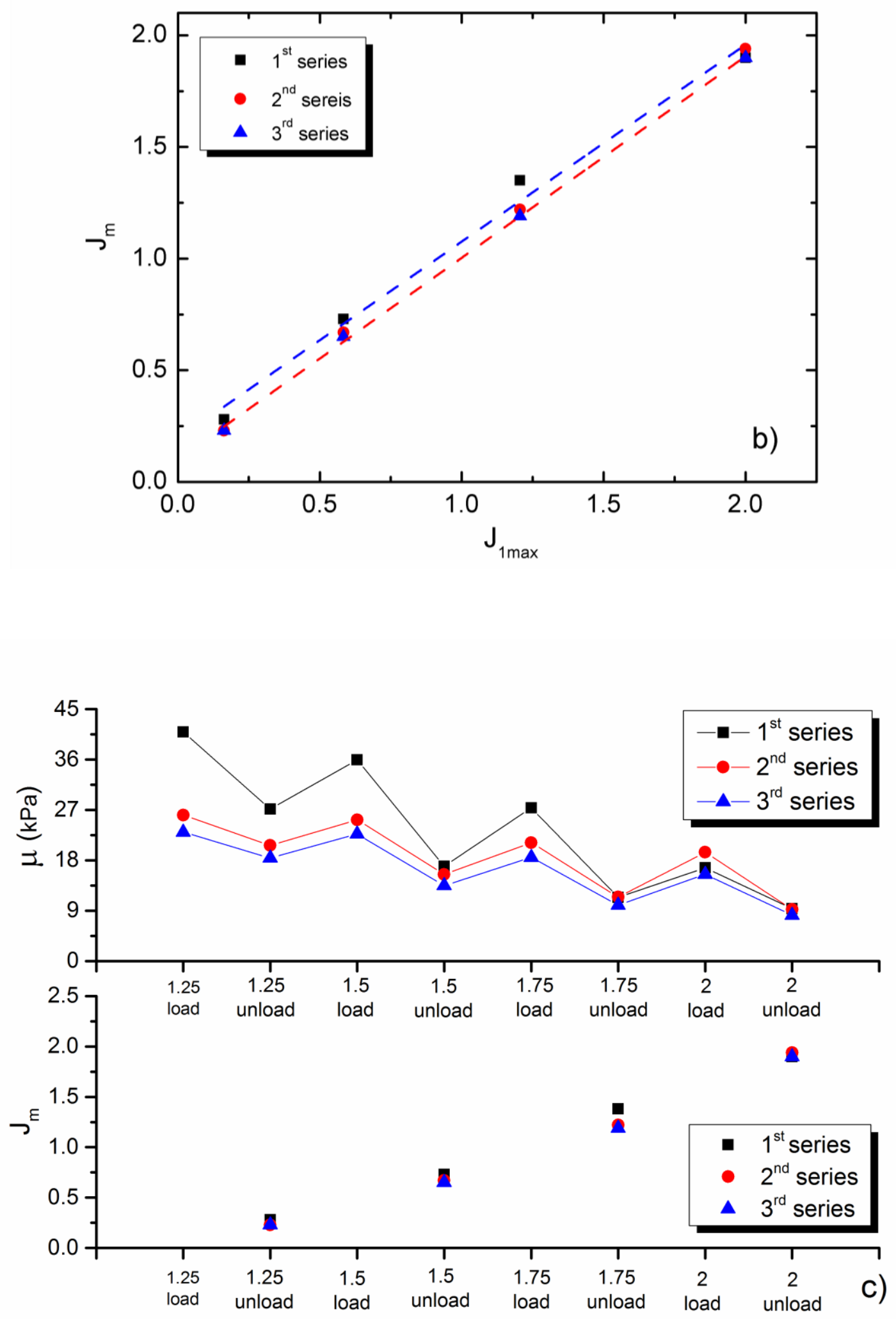
Figure 4 Gent model parameter fits giving a) unloading shear modulus $\left(\mu_{U}\right)$; and b) maximum extensibility $\left(\mathrm{J}_{\mathrm{m}}\right)$ varying with historic deformation maximum in three load/unload series; c) the evolution of loading, unloading shear modulus and $\mathrm{J}_{\mathrm{m}}$ in sequential load/unload cycles characterized by $\lambda_{\max }$. Each load/unload series is as defined in Figure 1 .

Figure $4 \mathrm{c}$ ) lists the variation of $\mu_{\mathrm{L}}, \mu_{\mathrm{U}}$ and $\mathrm{J}_{\mathrm{m}}$ in sequential load/unload cycles for each test series. In addition to illustrating a damage process, the parameters also demonstrate the recoverability of mechanical properties of the hybrid gel. For instance, in each series, the shear modulus of the reloading curve in the subsequent cycle is always larger than that of the previous unloading curve, indicating the recovery of network strand density. Second, the network topology of the hybrid gel is shown to be fully-retrieved in the $3^{\text {rd }}$ series compared with the $2^{\text {nd }}$ series. This is evidenced by the similar $\mu_{U}$ and almost identical $J_{m}$ fitted for the unloading curve of the same $\lambda_{\max }$ between the two series.

Wang and Hong ${ }^{19}$ have assumed the strand length distribution of the $1^{\text {st }}$ formed (tight) network in a DN gel to be a log-normal distribution. Two damage variables: $\eta$ and $J_{m}$ have been proposed as a function of historic deformation maximum $\left(\lambda_{\max }\right)$ to describe the fracture mechanism of the DN gel. $\eta$ represents the stiffness of the damaged gel with respect to that of the virgin gel (thus, $\eta \leq 1$ ) while $\mathrm{J}_{\mathrm{m}}$ has the similar meaning to the Gent model, characterizing the maximum extensibility of the damaged gel. The model was adapted here to fit experimental $\eta$ and $J_{m}$ to determine the model parameters: $\lambda_{0}, d, J_{0}, \alpha$, and $\eta_{\mathrm{o}}$ (defined below) in each series of load/unload tests. Load/unload curves were then plotted using these parameters and compared with the experimentally measured curves. 
The estimation of $\eta$ given by the W-H model is shown in equation (4) where $\mathrm{d}$ is the width of the strand length distribution, $\lambda_{\mathrm{o}}$ is the median of the distribution, and $\eta_{\mathrm{o}}$ is a normalization parameter. In the $\mathrm{W}-\mathrm{H}$ model, the physical meaning of $1-\eta_{\mathrm{o}}$ represents the ratio between the stiffness of the fully-damaged DN gel and that of the virgin gel. In the present work, the value of $\eta_{\mathrm{o}}$ was fixed at 0.9 when applying the model to the $1^{\text {st }}$ series, and the same value has been also used in our previous work $\frac{17}{}$ and in Hong and Gong's work $\stackrel{15,19}{\text {. The }}$ initial load/unload series was conducted on the gel in its virgin state. Hence, the theoretical $\eta$ is considered to change from unity. The shear modulus of each unloading curve determined from the Gent model was divided by the initial shear modulus of the virgin gel to obtain serial experimental $\eta$. The $\eta$ fits are illustrated in Figure 5 where the blue dashed lines are fitted $\eta\left(\lambda_{\max }\right)$ and red squares are experimental $\eta$. For clarity, in the following text, $\eta\left(\lambda_{\max }\right)$ in the $1^{\text {st }}, 2^{\text {nd }}$, and $3^{\text {rd }}$ series are denoted as $\eta_{1}\left(\lambda_{\max }\right), \eta_{2}\left(\lambda_{\max }\right)$ and $\eta_{3}\left(\lambda_{\max }\right)$, respectively.

$\eta\left(\lambda_{\max }\right)=1-\frac{\eta_{\mathrm{o}}}{2}\left[\operatorname{erf}\left(\frac{1}{\sqrt{2} \mathrm{~d}} \ln \frac{\lambda_{\max }-1}{\lambda_{\mathrm{o}}-1}\right)+1\right]$ 


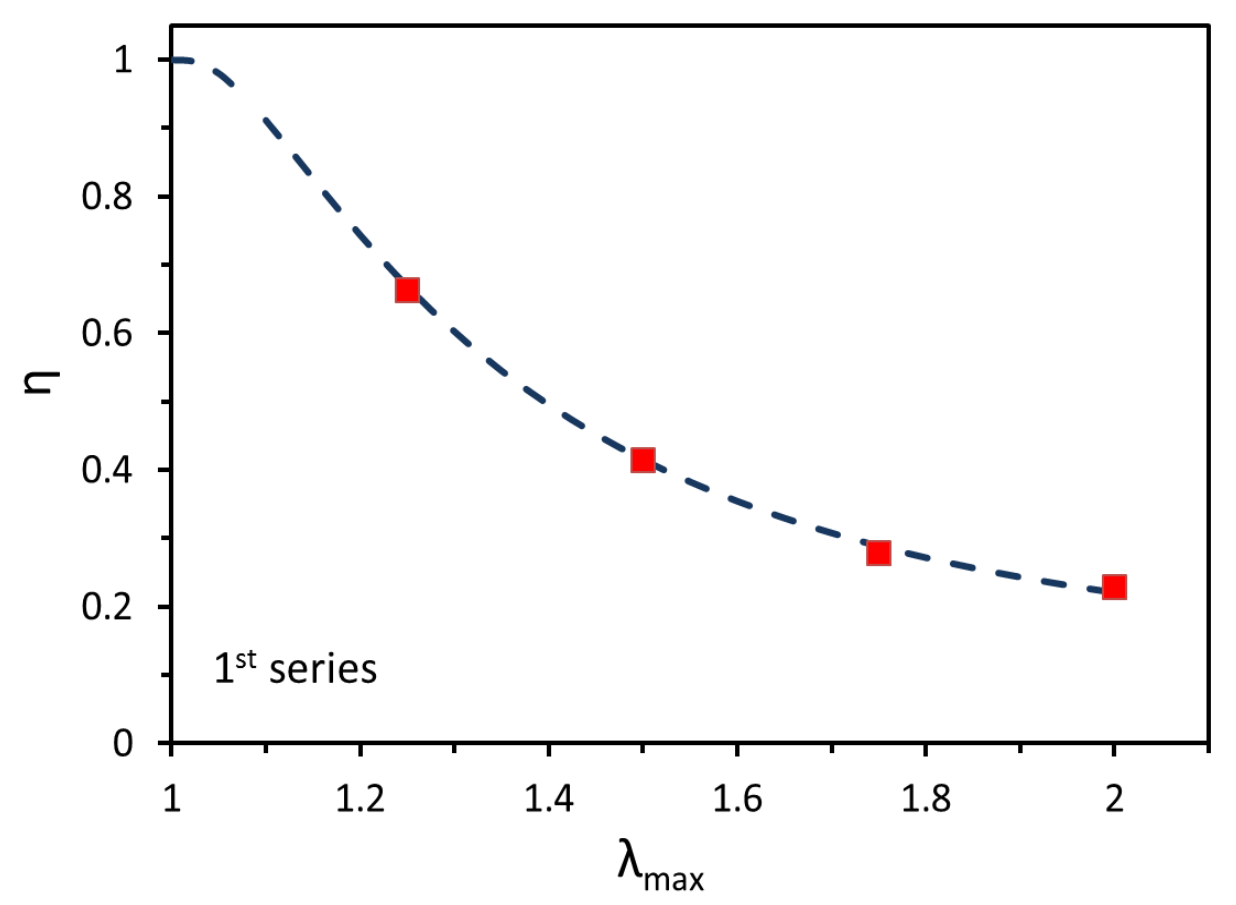

Figure $5 \eta$ fits applying original W-H model to the $1^{\text {st }}$ load/unload series on virgin gel.

After the hybrid gel underwent the $1^{\text {st }}$ load/unload series, a $1 \mathrm{~mm}$ permanent strain $\left(\varepsilon_{\mathrm{p}}\right)$ was observed and it was maintained in the following mechanical tests. Since all the $\lambda$ and stresses in the three series of load/unload tests were calculated with respect to the virgin gel dimensions, the first-loading curve in the $2^{\text {nd }}$ and $3^{\text {rd }}$ series should start from an extension ratio of $\left(1+\varepsilon_{\mathrm{p}}\right)$. In the present work, $\varepsilon_{\mathrm{p}}=0.08$. Meanwhile, the initial shear modulus of the virgin gel was not fully recovered in the subsequent series. As a result, instead of unity, $\eta_{2}$ $\left(\lambda_{\max }\right)$ should evolve from $\frac{\mu_{2}}{\mu_{1}}$ and $\eta_{3}\left(\lambda_{\max }\right)$ from $\frac{\mu_{3}}{\mu_{1}}$ where $\mu_{2}$ and $\mu_{3}$ are initial shear moduli at the beginning of the $2^{\text {nd }}$ and $3^{\text {rd }}$ series, respectively, and $\mu_{1}$ is the initial shear modulus of the virgin gel. $\eta_{\mathrm{o}}$ also needs to be re-calculated as $\frac{\mu_{2}}{\mu_{1}}-0.1$ for the $2^{\text {nd }}$ series and $\frac{\mu_{3}}{\mu_{1}}-0.1$ for $3^{\text {rd }}$ series. Equation (4) is thereby modified into equation (5) and (6) to fit experimental $\eta$ in the $2^{\text {nd }}$ and $3^{\text {rd }}$ series, respectively. 


$$
\begin{aligned}
& \eta_{2}\left(\lambda_{\max }\right)=\frac{\mu_{2}}{\mu_{1}}-\frac{\eta_{\mathrm{o}}}{2}\left[\operatorname{erf}\left(\frac{1}{\sqrt{2} \mathrm{~d}} \ln \frac{\lambda_{\max }-1-\varepsilon_{\mathrm{p}}}{\lambda_{\mathrm{o}}-1-\varepsilon_{\mathrm{p}}}\right)+1\right] \\
& \eta_{3}\left(\lambda_{\max }\right)=\frac{\mu_{3}}{\mu_{1}}-\frac{\eta_{\mathrm{o}}}{2}\left[\operatorname{erf}\left(\frac{1}{\sqrt{2} \mathrm{~d}} \ln \frac{\lambda_{\max }-1-\varepsilon_{\mathrm{p}}}{\lambda_{\mathrm{o}}-1-\varepsilon_{\mathrm{p}}}\right)+1\right]
\end{aligned}
$$

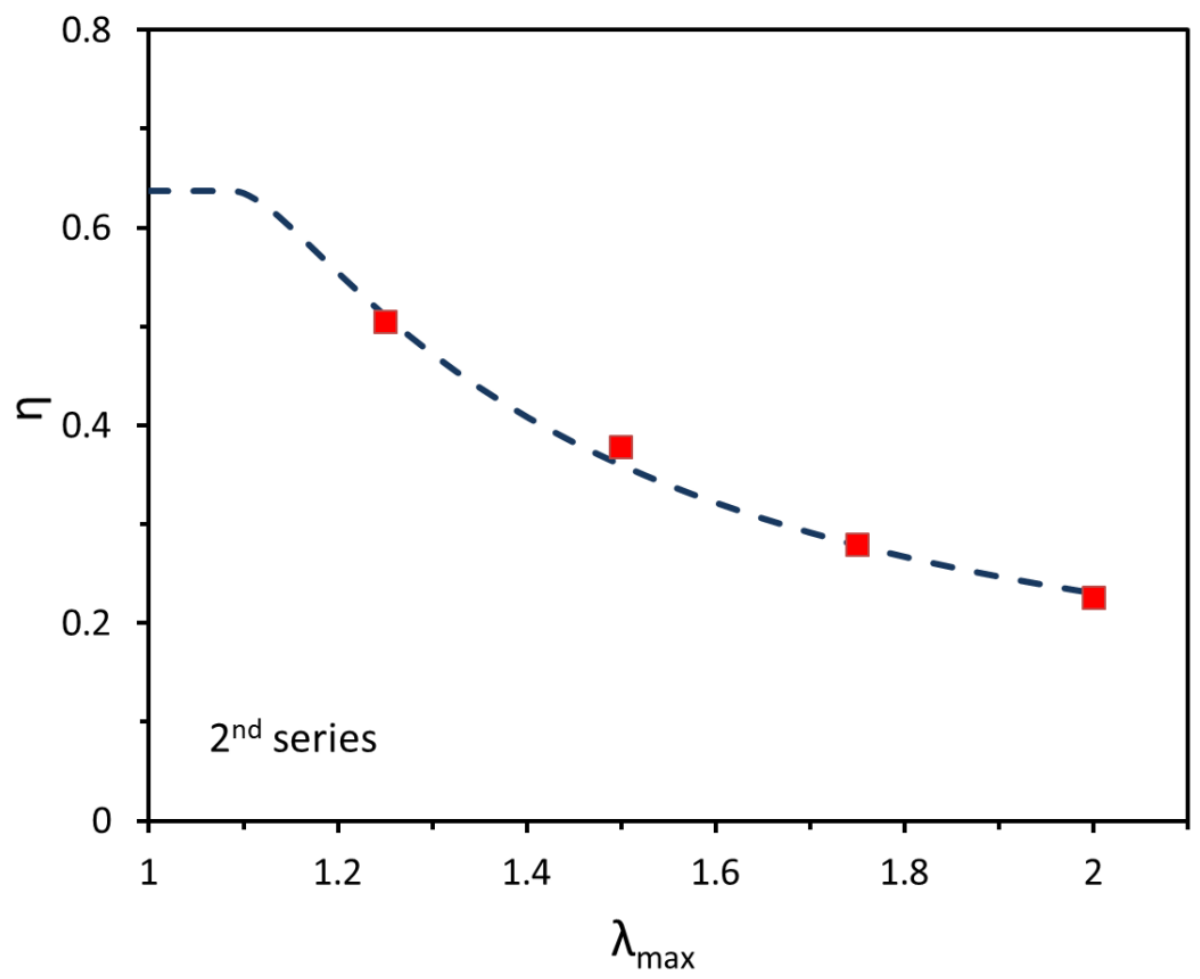




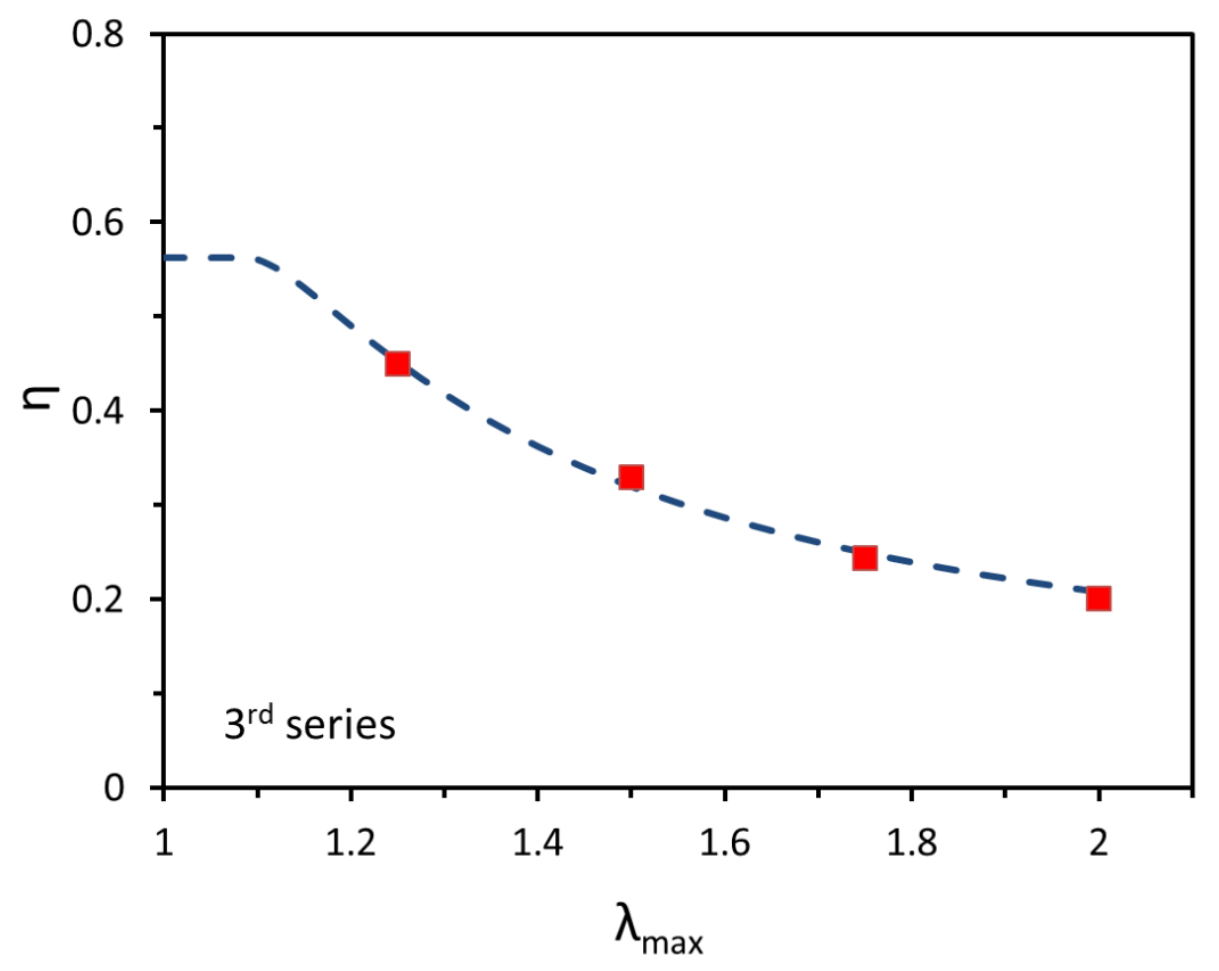

Figure $6 \eta$ fits applying modified W-H model to the $2^{\text {nd }}$ and $3^{\text {rd }}$ load/unload series applied to the gel after the first and second recovery periods, respectively.

Figure 5 and 6 clearly show that $\eta_{1}\left(\lambda_{\max }\right), \eta_{2}\left(\lambda_{\max }\right)$ and $\eta_{3}\left(\lambda_{\max }\right)$ are able to provide agreeable fits to the experimental data. The calculated $\eta$ monotonically decreases with $\lambda_{\max }$, suggesting that in all three load/unload series, the hybrid gel was softening when it was deformed above its historic maximum extension. Wang and Hong $\underline{19}$ have assumed the stretching limit of the damaged gel $\mathrm{J}_{\mathrm{m}}$ to be a linear function with $\mathrm{J}_{1 \max }$ as shown by equation (7) where the first strain invariant $\mathbf{J}_{1 \max }$ is calculated in terms of $\lambda_{\max }$ using equation (8). Gent model fits of $\mathrm{J}_{\mathrm{m}}$ for the unloading curves were used as experimental $\mathrm{J}_{\mathrm{m}}$. Equations (7) and (8) were fitted to the experimental $\mathrm{J}_{\mathrm{m}}$ obtained from the $1^{\text {st }}$ series to generate two model parameters: $J_{o}$ and $\alpha$. Since the sample gel showed a permanent strain after the $1^{\text {st }}$ series, the original $J_{1 \max }\left(\lambda_{\max }\right)$ shown in equation (8) should be re-written into equation (9) for the $2^{\text {nd }}$ 
and $3^{\text {rd }}$ series. By using the modified $\mathrm{J}_{1 \max }\left(\lambda_{\max }\right)$, experimental $\mathrm{J}_{\mathrm{m}}$ in the subsequent two series were fitted, and $\mathrm{J}_{\mathrm{o}}$ and $\alpha$ were obtained. Figure 7 demonstrates the $\mathrm{J}_{\mathrm{m}}$ fits using the original and modified $\mathrm{W}-\mathrm{H}$ model for the $1^{\text {st }}$ and the subsequent two series, respectively. The red squares denote experimental $\mathbf{J}_{\mathrm{m}}$ obtained from Gent model while the blue dashed lines are fitted $\mathbf{J}_{\mathrm{m}}\left(\mathrm{J}_{1 \max }\right)$ for the three series of test. As predicted by the $\mathrm{W}-\mathrm{H}$ model, a linear increase of $\mathbf{J}_{\mathrm{m}}$ with $\mathbf{J}_{1 \max }$ is observed. It should be noted here that the permanent strain appeared in the last unloading curve of the $1^{\text {st }}$ series so the related $\mathrm{J}_{1 \max }$ also needs to be evaluated using equation (9) to give a more accurate $\mathrm{J}_{\mathrm{m}}$ fits for the series.

$\mathrm{J}_{\mathrm{m}}=\mathrm{J}_{\mathrm{o}}+\alpha \mathrm{J}_{1 \max }$

$\mathrm{J}_{1 \max }=\lambda_{\max }{ }^{2}+2 \lambda_{\max }{ }^{-1}-3$

$\mathrm{J}_{1 \max }=\left(\lambda_{\max }-\varepsilon_{\mathrm{p}}\right)^{2}+2\left(\lambda_{\max }-\varepsilon_{\mathrm{p}}\right)^{-1}-3$

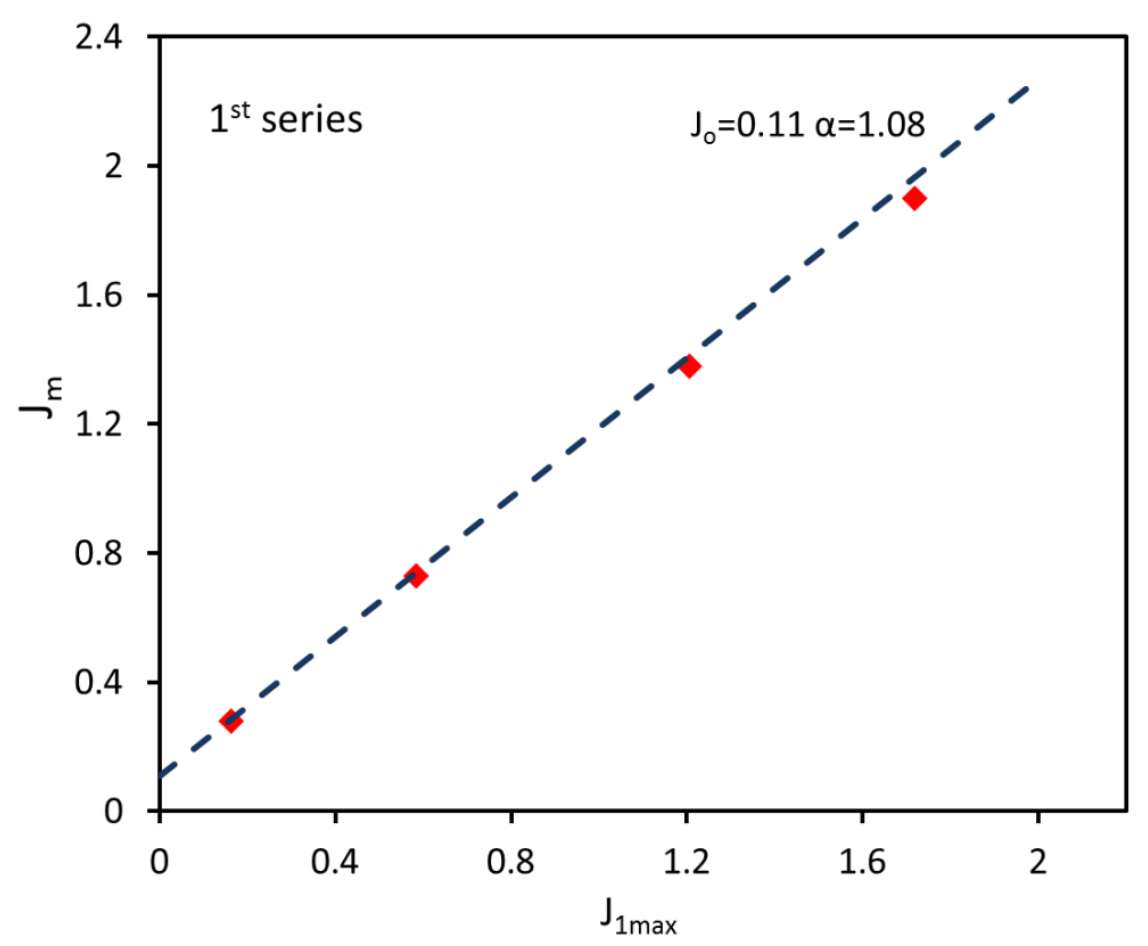



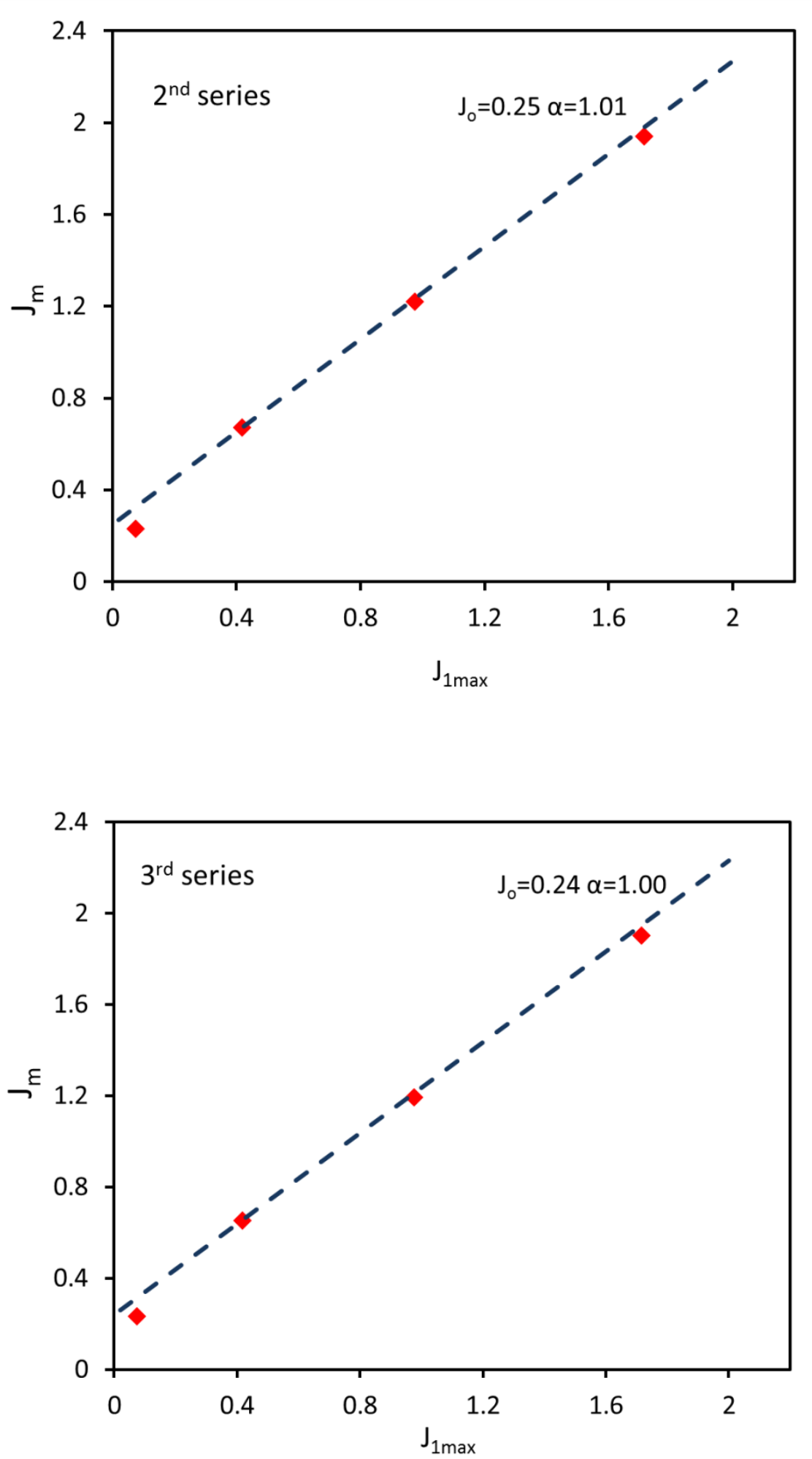

Figure $7 \mathrm{~W}-\mathrm{H} \mathrm{J}_{\mathrm{m}}$ fits for three series of load/unload tests as defined in Figure 1. 
Table 1 Parameters fits of W-H model for three series of load/unload test.

\begin{tabular}{cccccc}
\hline & $\lambda_{\mathrm{o}}$ & $\mathrm{d}$ & $\mathrm{J}_{\mathrm{o}}$ & $\alpha$ & $\eta_{\mathrm{o}}$ \\
\hline $1^{\text {st }}$ series & 1.35 & 0.96 & 0.11 & 1.08 & 0.9 \\
$2^{\text {nd }}$ series & 1.48 & 1.20 & 0.25 & 1.01 & 0.54 \\
$3^{\text {rd }}$ series & 1.47 & 1.19 & 0.24 & 1.00 & 0.46 \\
\hline
\end{tabular}

When four model parameters were obtained (Table 1), they were used to estimate the load/unload stress curves for each of the three series. The parameters for series 2 and 3 are almost identical and are also likely to apply to subsequent load/unload series. Two equations provided in the original $\mathrm{W}-\mathrm{H}$ model were written in terms of $\lambda$ and used to calculate the unloading and loading stress in the $1^{\text {st }}$ series, respectively. If $\lambda$ did not exceed the historic maximum $\left(\lambda \leqslant \lambda_{\max }\right)$, equation (10) was used to calculate the unloading or subsequent reloading stress. If the deformation exceeding the historic maximum, the loading stress was calculated with equation (11) on the basis of the present $\lambda$ to which the sample was stretched. The modified $\eta\left(\lambda_{\max }\right)$ and $\mathrm{J}_{1 \max }\left(\lambda_{\max }\right)$ as introduced above were substituted into the two equations to calculate the load/unload stress for $2^{\text {nd }}$ and $3^{\text {rd }}$ series.

$1^{\text {st }}$ series unloading

$$
\sigma=\mu_{1} \eta_{1}\left(\lambda_{\max }\right)\left(\lambda-\lambda^{-2}\right) /\left[1-\frac{\left(\lambda^{2}+2 \lambda^{-1}-3\right)}{J_{o}+\alpha\left(\lambda_{\max }{ }^{2}+2 \lambda_{\max }{ }^{-1}-3\right)}\right]
$$

$1^{\text {st }}$ series loading

$$
\sigma=\mu_{1} \eta_{1}(\lambda)\left(\lambda-\lambda^{-2}\right) /\left[1-\frac{\left(\lambda^{2}+2 \lambda^{-1}-3\right)}{\mathrm{J}_{0}+\alpha\left(\lambda^{2}+2 \lambda^{-1}-3\right)}\right]
$$


$2^{\text {nd }}$ and $3^{\text {rd }}$ series unloading

$\sigma=\mu_{1} \eta\left(\lambda_{\max }\right)\left[\left(\lambda-\varepsilon_{\mathrm{p}}\right)-\left(\lambda-\varepsilon_{\mathrm{p}}\right)^{-2}\right] /\left\{1-\frac{\left(\lambda-\varepsilon_{\mathrm{p}}\right)^{2}+2\left(\lambda-\varepsilon_{\mathrm{p}}\right)^{-1}-3}{\mathrm{~J}_{\mathrm{o}}+\alpha\left[\left(\lambda_{\max }-\varepsilon_{\mathrm{p}}\right)^{2}+2\left(\lambda_{\max }-\varepsilon_{\mathrm{p}}\right)^{-1}-3\right]}\right\}$

Where $\eta\left(\lambda_{\max }\right)=\eta_{2}\left(\lambda_{\max }\right)$ for $2^{\text {nd }}$ series (equation 5) and $\eta\left(\lambda_{\max }\right)=\eta_{3}\left(\lambda_{\max }\right)$ for $3^{\text {rd }}$ series (equation 6)

$2^{\text {nd }}$ and $3^{\text {rd }}$ series loading

$\sigma=\mu_{1} \eta(\lambda)\left[\left(\lambda-\varepsilon_{\mathrm{p}}\right)-\left(\lambda-\varepsilon_{\mathrm{p}}\right)^{-2}\right] /\left\{1-\frac{\left(\lambda-\varepsilon_{\mathrm{p}}\right)^{2}+2\left(\lambda-\varepsilon_{\mathrm{p}}\right)^{-1}-3}{\mathrm{~J}_{\mathrm{o}}+\alpha\left[\left(\lambda-\varepsilon_{\mathrm{p}}\right)^{2}+2\left(\lambda-\varepsilon_{\mathrm{p}}\right)^{-1}-3\right]}\right\}$

Where $\eta(\lambda)=\eta_{2}(\lambda)$ for $2^{\text {nd }}$ series and $\eta(\lambda)=\eta_{3}(\lambda)$ for $3^{\text {rd }}$ series using the present $\lambda$ into equation (5) and (6)

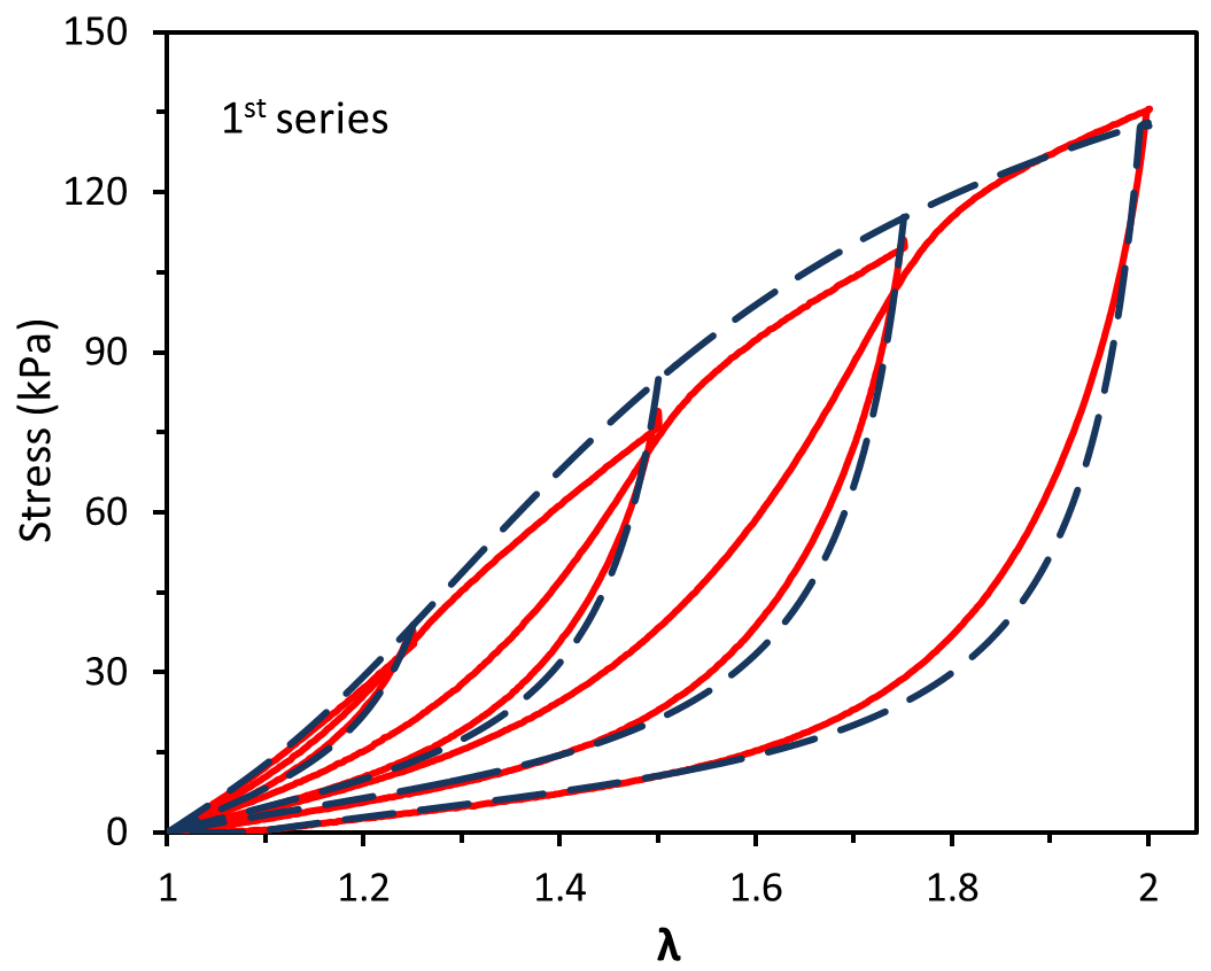



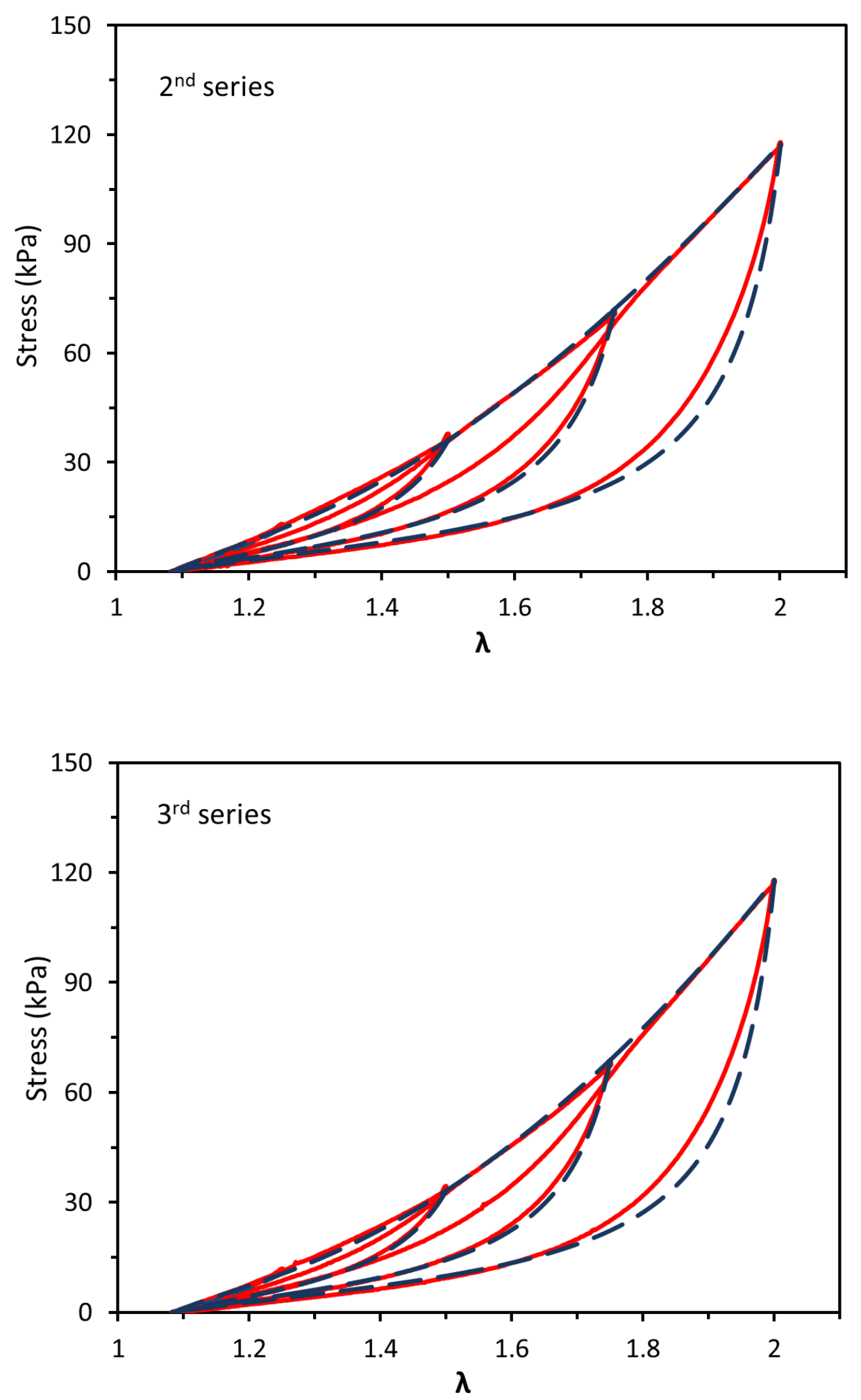

Figure 8 Estimate of load/unload stress using fitted W-H model parameters for both virgin $\left(1^{\text {st }}\right.$ series $)$ and gels after recovery periods $\left(2^{\text {nd }}\right.$ and $3^{\text {rd }}$ series $)$. 
In Figure 8, the red solid lines are measured load/unload stress and the blue dashed lines are $\mathrm{W}-\mathrm{H}$ fits. It is clear that the model is capable of providing very accurate predictions on the entire load/unload stress for each series. The model gives very good agreements to experimental $\eta, J_{m}$, and load/unload stress for both the virgin and recovered hybrid gel. The $\mathrm{W}-\mathrm{H}$ model is proposed to describe the chain scission process during loading of a DN gel assuming that the probability of $1^{\text {st }}$ network strands scission follows a log-normal distribution in terms of $\lambda$. Gent model fits suggest that the shortest alginate strands in the hybrid network are always fully-extended first to the contour length and lead to the unzipping of the ionic crosslinks. Therefore, the W-H model parameters give the probability distribution of chain scission and can be regarded as a description of the strand length or molecular weight distribution for the alginate strands. Equation (14) and (15) are the re-written log-normal probability density function (PDF) in terms of $\lambda$ that can be used to calculate the alginate chain scission probability for the $1^{\text {st }}$ series and $2^{\text {nd }}$ and $3^{\text {rd }}$ series, respectively.

$$
\begin{aligned}
& \mathrm{P}(\lambda)=\frac{1}{(\lambda-1) d \sqrt{2 \pi}} \exp \left\{-\frac{1}{2}\left[\frac{\ln (\lambda-1)-\ln \left(\lambda_{o}-1\right)}{d}\right]^{2}\right\} \\
& \mathrm{P}(\lambda)=\frac{1}{\left(\lambda-1-\varepsilon_{p}\right) d \sqrt{2 \pi}} \exp \left\{-\frac{1}{2}\left[\frac{\ln \left(\lambda-1-\varepsilon_{p}\right)-\ln \left(\lambda_{o}-1-\varepsilon_{p}\right)}{d}\right]^{2}\right\}
\end{aligned}
$$

As proposed recently for DN gels $\frac{17}{}$ the probability of strand scission can be equated to the concentration of network strands $\left(\mathrm{X}^{*}\right)$ by normalising the PDF to the overall network strand density $\left(\mathrm{N}^{*}\right)$ where the network strand length can be inferred by the extension ratio at which the strand is unloaded due to the dissociation of the ionic crosslinks at the strand ends. The total concentration of network strands is then given by: 
$\mathrm{N}^{*}=\int_{\lambda_{\mathrm{t}}}^{\infty} \mathrm{X}^{*}(\lambda) d \lambda$

Where $\lambda_{t}$ is the threshold extension ratio at which the shortest alginate chains are extended until the ionic crosslinks at the strand ends are pulled apart. The probability of the dissociation of the ionic crosslinks at any given extension ratio depends directly on the concentration of alginate network strands that are stretched to the point at which the ionic crosslinks fail. Consequently, the distribution of network strand lengths can be estimated as $\mathrm{X}^{*}(\lambda)=\mathrm{P}(\lambda) \mathrm{N}^{*}$ and the overall strand density can be determined from the measured shear modulus:

$\mu_{i}=\mathrm{N}_{i}^{*} \mathrm{RT}$

The subscript $i$ represents either the first, second or third loading cycle for the hybrid gel.

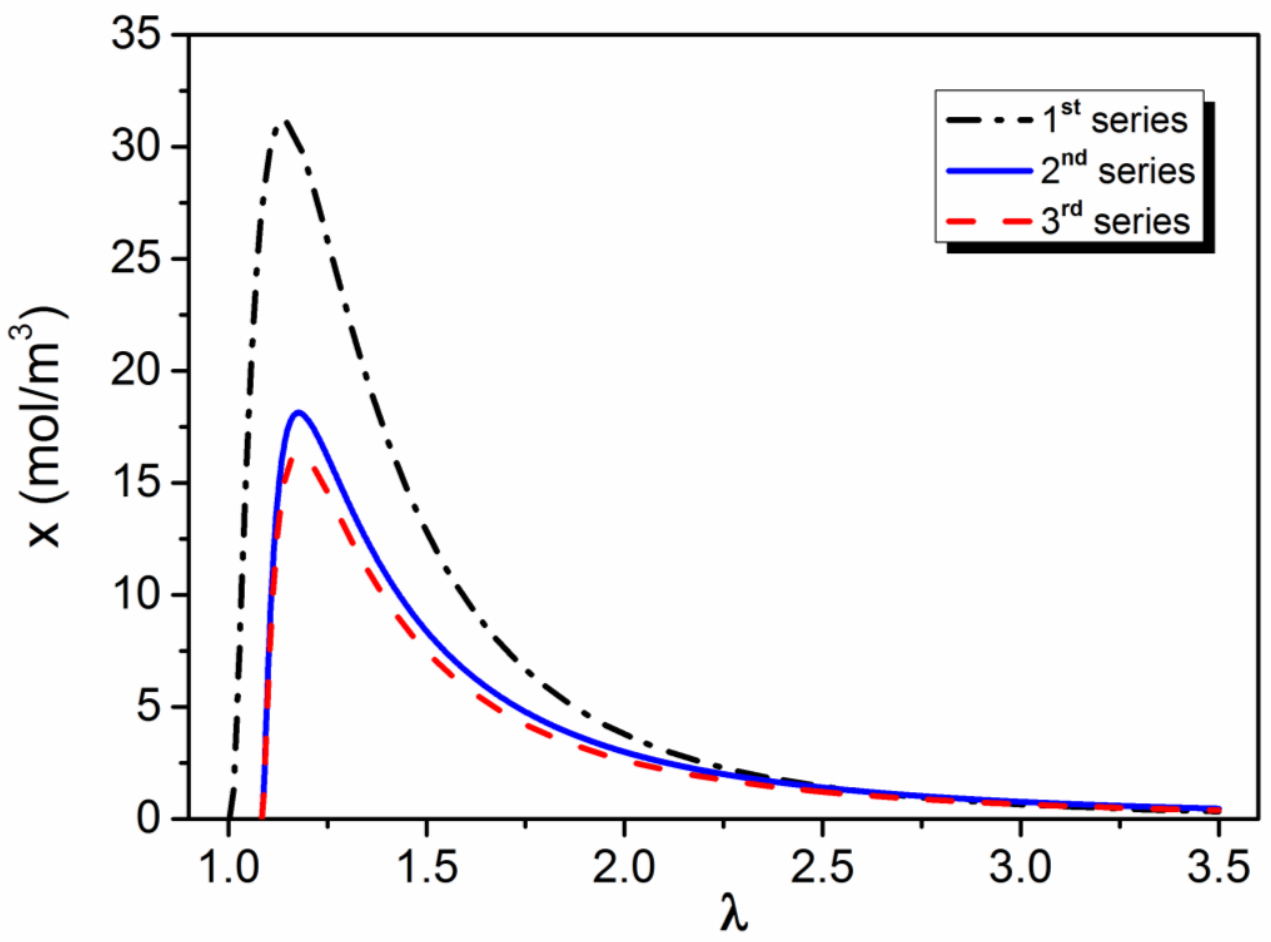


Figure 9 Estimated distribution of alginate strand concentrations $\left(X^{*}\right)$ for the virgin gel $\left(1^{\text {st }}\right.$ series) and gels after recovery periods $\left(2^{\text {nd }}\right.$ and $3^{\text {rd }}$ series $)$. The strand concentration represents the number of strands (per gel volume) stretched to the point of breaking at a given extension ratio.

Figure 9 illustrates the alginate strand distribution estimated from the three load/unload series and parameters fitted to the W-H model. The network strand distribution of the gel both initially and after one or two load/unload cycles are almost identical above an extension ratio $\lambda=2$ which was the maximum extension applied during the loading cycles. This observation is consistent with the mechanism that network damage starts during gel extension with the shortest network strands and then involves progressively longer strands as extension increases. Network strands that are not fully extended at the maximum extension are immune from damage. The strand density estimates shown in Figure 9 suggest that there was a considerable and permanent loss in the number of shorter alginate network strands during the first load/unload cycle. The first stretching cycle causes a reorganization of the alginate network with crosslinks between strands breaking during loading and reforming during the recovery period. For reasons that are not yet known, the number of strands that are reformed is smaller than originally produced during the initial formation of the alginate network by soaking in $\mathrm{Ca}^{2+}$ solution. Subsequent load/unload cycles to the same maximum extension appears to generate damage that can be fully recovered. 


\section{Conclusions}

The present research aims to investigate the mechanical recoverability and damage process of the ionic-covalent PAAm-alginate hybrid gel. The hybrid gels were prepared with a covalent crosslinker concentration of either $0.05 \mathrm{~mol} \%$ or $0.01 \mathrm{~mol} \%$. To investigate the mechanical recoverability of the obtained hybrid gel, three series of load/unload tests were sequentially carried out on the virgin gel and the gel after two recovery periods at zero stress. It was found that the mechanical properties of the tested gels were only fully reversible between the $2^{\text {nd }}$ and $3^{\text {rd }}$ series. Only partial recovery of mechanical properties was evident between the $1^{\text {st }}$ and $2^{\text {nd }}$ testing series. Both the size of the hysteresis and the initial shear modulus significantly decreased from the $1^{\text {st }}$ to the $2^{\text {nd }}$ series, for which the irreversible gel network re-construction initiated by the first loading was considered to be the major cause.

Unloading curves of each load/unload series were modelled by the Gent model. The calculated unloading stress agreed with the experimental curves very well. The variations of unloading shear modulus and the maximum extensibility parameter as a function of maximum extension $\left(\lambda_{\max }\right)$ demonstrate a damage process for the hybrid gel where the shortest alginate strands were stretched until the weak ionic crosslinks were pulled apart. This damage process leads to the decrease of strand density and increase of the length of remaining network strands.

The mechanical model proposed by Wang and Hong was evaluated for the prediction of the damage process during loading of the hybrid gels. The model was found to accurately estimate the load/unload stress for each series. Mechanical reversibility between the $2^{\text {nd }}$ and $3^{\text {rd }}$ series was evidenced by the fitted model parameters which were taken as the description 
of the gel network topologies. Those parameters were then used to plot alginate strand length distributions. The virgin gel showed a higher fraction of shorter alginate strands than remained after the initial loading. The method could be used in future work to assess the strand length distribution of hybrid gels prepared with different charged polymers and with different crosslinking ion concentrations. The model has previously been successfully applied to double network hydrogels $\frac{17}{2}$ and is likely to be generally applicable to polymer networks that suffer progressive chain scission without catastrophic crack propagation, such as nanocomposite gels.

\section{References}

(1) J. P. Gong, Y. Katsuyama, T. Kurokawa, Y. Osada, ADvanced Materials. 2003, 15, 1155-1158.

(2) K. Haraguchi, T. Takehisa, Advanced Materials. 2002, 14, 1120-1124.

(3) K. Ito, Polym. J. 2007, 39, 489-499.

(4) S. Ahmed, T. Nakajima, T. Kurokawa, M. A. Haque, J. P. Gong, Polymer. 2014, 55, 914-923.

(5) H. R. Brown, Macromolecules. 2007, 40, 3815-3818.

(6) Y. Tanaka, Europhys. Lett. 2007, 78, 56005.

(7) X. H. Zhao, Soft Matter. 2014, 10, 672-687.

(8) W. C. Lin, W. Fan, A. Marcellan, D. Hourdet, C. Creton, Macromolecules. 2010, 43, 25542563.

(9) J. Y. Sun, X. H. Zhao, W. R. K. Illeperuma, O. Chaudhuri, K. H. Oh, D. J. Mooney, J. J. Vlassak, Z. G. Suo, Nature. 2012, 489, 133-136.

(10) S. E. Bakarich, G. C. Pidcock, P. Balding, L. Stevens, P. Calvert, M. I. H. Panhuis, Soft Matter. 2012, 8, 9985-9988.

(11) G. T. Grant, E. R. Morris, D. A. Rees, P. J. C. Smith, D. Thom, FEBS Lett. 1973, 32, 195-198.

(12) I. Braccini, S. Perez, Biomacromolecules. 2001, 2, 1089-1096.

(13) J. P. Gong, Soft Matter. 2010, 6, 2583-2590.

(14) J. P. Gong, Science. 2014, 344, 161-162.

(15) T. Nakajima, T. Kurokawa, S. Ahmed, W. L. Wu, J. P. Gong, Soft Matter. 2013, 9, 1955-1966.

(16) R. E. Webber, C. Creton, H. R. Brown, J. P. Gong, Macromolecules. 2007, 40, 2919-2927.

(17) H. Xin, H. R. Brown, G. M. Spinks, Polymer. 2014, 55, 3037-3044.

(18) C. H. Yang, M. X. Wang, H. Haider, J. H. Yang, J. Y. Sun, Y. M. Chen, J. X. Zhou, Z. G. Suo, ACS Appl. Mater. Interfaces. 2013, 5, 10418-10422.

(19) X. Wang, W. Hong, Soft Matter. 2011, 7, 8576-8581.

(20) A. N. Gent, Rubber Chem. Technol. 1996, 69, 59-61.

(21) M. Rubinstein, R. H. Colby, Polymer Physics; Oxford University Press: Oxford, 2006. 


\section{Acknowledgements}

The authors gratefully acknowledge the partial financial support provided by the Australian Research Council through its Centres of Excellence and Professorial Fellowships programs. 